\title{
Defect Sink Characteristics of Specific Grain Boundary Types in 304 Stainless Steels Under High Dose Neutron Environments ${ }^{\dagger}$
}

\author{
Kevin G. Field, ${ }^{1 *}$ Ying Yang, ${ }^{2}$ Todd R. Allen, ${ }^{3}$ Jeremy T. Busby ${ }^{4}$ \\ 1,2,4 Oak Ridge National Laboratory, Oak Ridge, TN 37832, USA \\ ${ }^{3}$ Idaho National Laboratory, Idaho Falls, ID 83415, USA \\ ${ }^{1}$ fieldkg@ornl.gov \\ 2 yangying@ornl.gov \\ ${ }^{3}$ todd.allen@inl.gov \\ ${ }^{4}$ busbyjt@ornl.gov
}

*Corresponding author:

Kevin G. Field

Materials Science and Technology Division

PO Box 2008

Oak Ridge, TN 37832 (USA)

Phone: +1 6082624711

Email: fieldkg@ornl.gov

${ }^{\dagger}$ This manuscript has been authored by UT-Battelle, LLC under Contract No. DE-AC05-00OR22725 with the U.S. Department of Energy. The United States Government retains and the publisher, by accepting the article for publication, acknowledges that the United States Government retains a non-exclusive, paid-up, irrevocable, world-wide license to publish or reproduce the published form of this manuscript, or allow others to do so, for United States Government purposes. The Department of Energy will provide public access to these results of federally sponsored research in accordance with the DOE Public Access Plan (http://energy.gov/downloads/doe-public-access-plan). 


\title{
Defect Sink Characteristics of Specific Grain Boundary Types in 304 Stainless Steels Under High Dose Neutron Environments ${ }^{\dagger}$
}

\author{
Kevin G. Field, ${ }^{1 *}$ Ying Yang, ${ }^{2}$ Todd R. Allen, ${ }^{3}$ Jeremy T. Busby ${ }^{4}$ \\ 1,2,4 Oak Ridge National Laboratory, Oak Ridge, TN 37832, USA \\ ${ }^{3}$ Idaho National Laboratory, Idaho Falls, ID 83415, USA \\ ${ }^{1}$ fieldkg@ornl.gov \\ 2yangying@ornl.gov \\ ${ }^{3}$ todd.allen@inl.gov \\ ${ }^{4}$ busbyjt@ornl.gov
}

\begin{abstract}
Radiation induced segregation (RIS) is a well-studied phenomena which occurs in many structurally relevant nuclear materials including austenitic stainless steels. RIS occurs due to solute atoms preferentially coupling with mobile point defect fluxes that migrate and interact with defect sinks. Here, a 304 stainless steel was neutron irradiated up to $47.1 \mathrm{dpa}$ at $320^{\circ} \mathrm{C}$. Investigations into the RIS response at specific grain boundary types were utilized to determine the sink characteristics of different boundary types as a function of irradiation dose. A rate theory model built on the foundation of the modified inverse Kirkendall (MIK) model is proposed and benchmarked to the experimental results. This model, termed the GiMIK model, includes alterations in the boundary conditions based on grain boundary structure and expressions for interstitial binding. This investigation, through experiment and modeling, found specific grain boundary structures exhibit unique defect sink characteristics depending on their local structure. Such interactions were found to be consistent across all doses investigated and to have larger global implications, including precipitation of Ni-Si clusters near different grain boundary types.
\end{abstract}

Keywords: Steel, grain boundary, irradiation, segregation, misorientation, rate theory, sink strength

\footnotetext{
${ }^{\dagger}$ This manuscript has been authored by UT-Battelle, LLC under Contract No. DE-AC05-00OR22725 with the U.S. Department of Energy. The United States Government retains and the publisher, by accepting the article for publication, acknowledges that the United States Government retains a non-exclusive, paid-up, irrevocable, world-wide license to publish or reproduce the published form of this manuscript, or allow others to do so, for United States Government purposes. The Department of Energy will provide public access to these results of federally sponsored research in accordance with the DOE Public Access Plan (http://energy.gov/downloads/doe-public-access-plan).
} 


\section{Introduction}

Numerous light water reactor (LWR) nuclear power plants in the United States with operating licenses for 40 years have undergone license renewal processes to extend their operational lifetimes up to 60 years. The drive for these life extensions has been, in part, due to the high capital cost for new nuclear power plant construction in the United States. Recently, success in proving the viability of operating LWR plants up to 60 years and limited change (or no change) in the cost of new builds has sparked interest in life extensions to 80 years and beyond. Such long operational lifetimes would significantly increase the radiation dose absorbed by core internals in these nuclear power plants.

Additionally, an interest in fast neutron fission reactors and fusion power reactor technology has pushed the radiation dose design envelope of nuclear grade materials to displacement damage dose levels greater than typical LWR conditions $[1,2]$. Such high doses, for any nuclear power technology, could lead to significant changes in known radiation-induced processes such as radiation hardening and embrittlement, radiation-induced/enhanced precipitation, radiation-induced segregation (RIS), irradiation creep, volumetric swelling, and helium embrittlement [2]. Hence, new materials and/or novel processing routes capable of producing materials with enhanced radiation tolerance must be developed and verified.

A review by Zinkle et al. has shown the development of materials with point defect sink strengths above $\sim 10^{16} \mathrm{~m}^{-2}$ can significantly suppress several of the radiation-induced processes seen in nuclear materials, such as radiation-induced hardening [3]. Such studies have shown the importance of the sink density to irradiation resistance, particularly when high dose applications are desired. Studies have also shown the importance of the defect sink-matrix interface in determining the strength of a particular type of defect sink [4-7]. Therefore, the irradiation resistance of a material can be a superposition of both the density and the sink strength of any particular defect sink in the material of interest.

Several approaches have been applied/proposed to control both the sink density and/or the sink strength in metallic nuclear materials, including the addition of a high density of nano-scaled oxide particles in steels such as oxide dispersion strengthened (ODS) steels [8-18], grain boundary engineering to increase the density of grain boundaries of a certain type [19-21], and grain refinement to develop 
grain sizes approaching the nanometer scale level [22-24]. RIS can serve as a metric to assess the viability of such approaches because the phenomenon is directly related to the mobile point defect flux and annihilation/absorption to/at a defect sink or cluster of sinks. RIS in its simplest form is the segregation of solute and solvent at a defect sink that has occurred due to the preferential coupling of specific alloying elements to the interstitial and/or vacancy flux at said defect sink. By comparing the magnitude of the RIS response at different defect sinks where the diffusion and irradiation parameters remain known, the variances in the point defect interactions occurring at different defect sinks can be determined. Through the coupling of modeling and experiment, further information can be extracted about the relationship between mobile point defects and defect sinks, including mechanisms such as defect sink biasing, sink-defect interaction distances, and solute-defect diffusion rates.

RIS has been successfully used to investigate the sink characteristics of specific grain boundary types in both austenitic and ferritic/martensitic steels using experiments and modeling [25-36]. These studies have shown the grain boundary type, whether a low-angle grain boundary, random high-angle grain boundary, or low- $\Sigma$ coincident site lattice (CSL) boundary, will have different sink characteristics due to the local structure of the grain boundary and can be correlated to their coherency and hence grain boundary energetics. The majority of these studies were conducted using either ion irradiations or electron irradiations with no investigations at doses greater than $10 \mathrm{dpa}$. Such data provides an initial understanding on grain boundaries as sink interfaces but limits the ability to draw conclusions on the effectiveness of custom tailoring the density of grain boundary types for high-dose neutron environments such as those expected in life extended LWRs, fast fission reactors, and fusion power reactors. This study expands on these works by investigating the low to high dose ( $50 \mathrm{dpa})$ response of specific grain boundary types in a neutron irradiated 304 stainless steel irradiated at $320^{\circ} \mathrm{C}$ and relates the findings towards the tailoring of the grain boundary network of a metallic material to increase the radiation tolerance of a material for high dose applications. A 304 stainless steel was used due to its well-known characteristics under irradiation and well-developed models for RIS. 


\section{Materials and Methods}

\subsection{Experimental Procedure for RIS Quantification}

This study used an industrial grade AISI 304 austenitic stainless steel from core shroud material. The nominal composition in weight percent was $19.95 \% \mathrm{Cr}, 10.8 \% \mathrm{Ni}, 1.82 \% \mathrm{Mn}, 0.56 \% \mathrm{Si}, 0.53 \% \mathrm{Mo}$, $0.023 \% \mathrm{C}$, bal. Fe. The stainless steel specimens were annealed prior to being irradiated. The alloys were irradiated in the BOR-60 fast reactor at $\sim 320^{\circ} \mathrm{C}$ to $5.5,10.2$, and $47.1 \mathrm{dpa}$ with an average dose rate of $\sim 8 \times 10^{-7} \mathrm{dpa} / \mathrm{s}$ [37]. The irradiated specimens are part of a cooperative research program on irradiationassisted stress corrosion cracking (IASCC) [37, 38]. In previous reports of this program [39-47], the alloy of interest is referred to as "Alloy A" or "Heat A" with AS13 referring to the 5.5 dpa specimen, AS18 to the 10.2 dpa specimen, and AS23 to the 47.1 dpa specimen, for reference. Samples were prepared for scanning transmission electron microscopy (STEM) by mechanically polishing $3 \mathrm{~mm}$ diameter discs punched from acquired parent material to a thickness less than $\sim 100 \mu \mathrm{m}$ followed by electropolishing at $12^{\circ} \mathrm{C}$ in a methanol:sulfuric $(7: 1)$ solution using a Struers Tenupol polishing unit.

A Philips CM200 FEG S/TEM operated in STEM mode with an accelerating voltage of $197 \mathrm{kV}$ that is equipped with an EDAX energy dispersive X-ray spectrometer (EDS) detector was used. The accelerating voltage is the result of a post column energy filter being activated during STEM-EDS acquisition. Grain boundaries were investigated using 2D EDS spectrum maps. Spectrum images were taken with a $50 \mathrm{~nm} \times 50 \mathrm{~nm}$ region-of-interest using $25 \times 25$ pixels with the grain boundary orientated running top to bottom in the image. An incident probe size of $1.5 \mathrm{~nm}$ with $\sim 1 \mathrm{nA}$ of probe current was used, and acquisition was taken with 1.5 second dwell times and a drift correction every 19 pixels. Quantification of elements was completed using the Cliff-Lorimer quantification scheme assuming a normalized alloy composition with $\mathrm{Fe}, \mathrm{Cr}, \mathrm{Ni}, \mathrm{Mn}$, and $\mathrm{Si}$. Experimentally determined ' $\mathrm{k}$ ' factors were calculated assuming the normalized alloy composition. Spectrum images were binned parallel to the boundary to increase counting statistics and provide an average 1D profile along the length of the grain boundary. Conditions were selected in an attempt to balance the EDS counting statistics during acquisition against issues with specimen drift and maintaining reasonable total acquisition times. Average 
profiles were fitted to a single Gaussian peak to determine peak height and profile full-width-at-halfmaximum (FWHM). Error bars are reported using one standard deviation of the mean through binning.

The grain boundary type was determined by calculating the misorientation angle and axis using the diffracted Kikuchi patterns of each grain taken immediately following spectrum imaging. Diffracted Kikuchi patterns were taken at a calibrated camera length of $119 \mathrm{~mm}$ at the CCD. Patterns were indexed assuming a face-centered cubic (FCC) grain boundary structure using custom software [48]. Calculated misorientation angle/axis pairs were evaluated using the Brandon criteria [49] to determine whether random high angle (HA) grain boundaries were low- $\Sigma(<27)$ CSL grain boundaries.

\subsection{GiMIK Rate Theory Model Description}

\subsubsection{MIK model and GiMIK model}

The modified inverse Kirkendall (MIK) model for Fe-Cr-Ni alloys by Allen et al. [50] has been widely used to predict RIS in irradiated austenitic (FCC) stainless steels. The MIK model was developed from the Perks' model [51]. Both models assume that RIS is due to an inverse Kirkendall mechanism. These two models are essentially the same except that the vacancy migration energy is local-composition dependent in the MIK model but constant in the Perks' model. The MIK model calculates vacancy migration energies from pair interactions based on thermodynamic quantities such as cohesive energies, vacancy formation energies, and ordering energies. This unique feature allows the MIK model to predict RIS in a wide range of Fe-Cr-Ni alloys with different compositions using a single set of parameters. As such, the MIK model was used here as the foundation of a refined model which incorporates grain boundary structure effects and interstitial binding.

To differentiate the base MIK model from the model used here, the acronym GiMIK (Grain boundary-Interstitial-Modified Inverse Kirkendall) is used to describe the model that incorporates grain boundary structure and interstitial binding effects. It should be noted the models (Perks', MIK, and GiMIK) are based on continuous diffusion theory and thus only point defects (vacancy of self-interstitialatom) are considered. It is recognized that the radiation-induced defects and resulting diffusion are quite complex in the Fe-Cr-Ni and Fe-Cr-Ni-Si systems. Thus, such simplifying assumptions must be made, 
especially when considering alloys that exist away from the dilute limit like the one studied here. Such simplifying assumptions allow for the diffusion equations to be extrapolated into the complex $\mathrm{Fe}-\mathrm{Cr}-\mathrm{Ni}$ or Fe-Cr-Ni-Si systems. For the original MIK model, this assumption has been shown to be reasonable because it has successfully described a large collection of experimental data of Fe-Cr-Ni alloys [50, 5254]; therefore, this assumption is used here.

The basic differential rate equations for point defects and solutes used by the Perks' and MIK models are used in the GiMIK model. The input parameters for the GiMIK model, including the symbols, their definitions, and values used in the calculations, are summarized in Table 1. The model parameters for $\mathrm{Fe}, \mathrm{Cr}$ and $\mathrm{Ni}$ were taken from Allen et al. [50]. All calculated concentration profiles from the GiMIK model were convoluted with an electron beam intensity distribution function $[55,56]$ based on the experimental parameters to allow for direct comparisons between experiment and model. The implementation of the grain boundary structure factors and interstitial binding in the GiMIK model are discussed below.

\subsubsection{Implementation of grain boundary structure effects}

To describe the RIS response of specific grain boundary types based on structure, the boundary conditions at the grain boundary in the MIK model needs to be modified because the existing MIK model treats grain boundaries as perfect sinks for mobile point defects. In this formalism, the RIS response of specific grain boundary types cannot be accurately evaluated as the perfect sink criteria maintains the point defect concentration at thermodynamic equilibrium at the boundary. Recent work by several authors has indicated that the perfect sink formalization used in typical rate theory models does not account for the RIS response seen at different grain boundary types/structures in both FCC and body centered cubic irradiated steels $[25,26,29,30,32,33,36]$. To overcome this deficiency, the MIK model was modified using the alternative boundary conditions developed by Duh et al. [31].

The boundary conditions developed by Duh et al. loosen the constraints on the concentration of point defects on the grain boundary and modify the sink strength assuming the grain boundary misorientation angle is a descriptor for its structure and hence sink characteristics. The boundary 
conditions allow one to simulate the RIS at different grain boundary types, including low-angle grain boundaries, low- $\Sigma$ CSL grain boundaries, and random HA grain boundaries. A detailed description of this formalism can be found in Refs. [31, 32]; it is briefly outlined here.

Duh et al. described the grain boundary as a pure symmetric tilt boundary consisting of an array of parallel edge dislocations, which are primary dislocations for a low-angle boundary or secondary dislocations for a singular or vicinal high-angle boundary. It is assumed that individual dislocations that comprise a grain boundary are perfect sinks for mobile point defects. The density of dislocations, $\rho$, along a grain boundary are estimated as

$$
\begin{gathered}
\rho_{H A}=\frac{4 \delta}{b} \sin \left(\frac{\Delta \theta}{2}\right) \quad(\text { high angle }) \\
\rho_{L A}=\frac{\theta}{b} \quad(\text { low angle) }
\end{gathered}
$$

Where $\delta$ is the thickness of the boundary, which is assumed as one atomic layer and $\theta$ is the misorientation angle for low angle grain boundaries and the angle of deviation from an exact CSL (singular) grain boundary for HA grain boundaries. The flux of defects into and along the grain boundary is modeled explicitly and thus the concentration of defects averaged over the boundary can vary depending on the local structure (or misorientation angle) of the boundary.

At the grain boundary, the rate equations for the vacancy concentration can be written as

$$
\Delta x \frac{\partial C_{V}}{\partial t}=\Omega J_{V}^{1}-\Omega J_{V}^{0}+\Delta x \eta K_{0}-\Delta x R C_{V} C_{I}
$$

Where $J_{V}^{1}$ and $J_{V}^{0}$ (number of defects, $\cdot \mathrm{m}^{-2} \cdot \mathrm{s}^{-1}$ ) are the flux of vacancies flowing into and out of the region directly adjacent to the grain boundary. $\Delta x(\mathrm{~m})$ is the width of the region between $J_{V}^{1}$ and $J_{V}^{0} . \Omega\left(\mathrm{m}^{-3}\right), R\left(\mathrm{~s}^{-}\right.$ $\left.{ }^{1}\right)$, and $\eta K_{0}\left(\mathrm{~s}^{-1}\right)$ are the atomic volume, the recombination coefficient, and the effective damage rate. The Frenkel-pair damage production mode is used here. Only single vacancy and interstitial are considered in the MIK and GiMIK model, as discussed previously. $C_{V}$ and $C_{I}$ are the number fractions of vacancies and interstitials, without unit. The flux $J_{V}^{0}$ for singular/vicinal (CSL) high-angle and low-angle grain boundaries can be written as (where the subscripts $\mathrm{v}$ and $\mathrm{k}$ designate a vacancy or elemental species, respectively): 


$$
\begin{array}{r}
J_{V}^{0}=2 \frac{S_{H}\left(C_{V}-C_{V}^{e q}\right) g_{V} a^{2} Z_{V} f_{V}^{g b} \sum v_{V K}^{0} C_{K} \exp \left(-\frac{E_{V K}^{m}}{k T}\right)}{\Omega} \delta \frac{2}{b_{H}} \sin \left(\frac{\Delta \theta_{H}}{2}\right) \quad \text { (high angle) } \\
J_{V}^{0}=\frac{S_{L}\left(C_{V}-C_{V}^{e q}\right) g_{V} a^{2} Z_{V} f_{V}^{g b} \sum v_{V K}^{0} C_{K} \exp \left(-\frac{E_{V K}^{m}}{k T}\right)}{\Omega} \frac{2}{b_{L}} \frac{\theta_{L}}{2} \quad \text { (low angle) }
\end{array}
$$

The symbols, their definitions, and the values used in the calculation are summarized in Table 2.

\subsubsection{Implementation of interstitial binding for Si segregation}

The MIK model is sufficient to describe the RIS for major elements $\mathrm{Fe}, \mathrm{Cr}$, and $\mathrm{Ni}$ through the inverse Kirkendall mechanism. To describe the segregation of Si, which was attributed to the preferential coupling between interstitial flux and undersized solutes, the interstitial binding model proposed by Wiedersich et al. [57] has been incorporated into the MIK model with the grain boundary structure effects to form the GiMIK model. The interstitial binding model states the partial diffusion coefficient of atom $\mathrm{Si}$ through interstitials, $i$, is:

$$
D_{S i}^{i}=\frac{1}{6} b_{i}^{2} z_{i} v_{S i}^{i} \frac{c_{S i}^{i}}{C_{S i}}
$$

where $b_{i}$ is the jump distance to the nearest-neighbor interstitial site, $z_{i}$ is the interstitial site coordination number, $v_{S i}^{i}$ is the jump frequency of a Si atom interstitial to a given nearest-neighbor interstitial site, and $\frac{C_{S i}^{i}}{C_{S i}}$ is the fraction of Si-atoms in the interstitial sites. For random occupation of interstitials by $S i$ - atoms, $C_{S i}^{i}=C_{i} C_{S i}$, where $C_{i}$ is the total interstitial concentration. For undersized solutes that form preferential solute-interstitial complexes, the fraction of $\mathrm{Si}$ atoms can be adequately represented by

$$
C_{S i}^{i}=C_{i} \frac{C_{S i} \exp \left(E_{S i-i}^{b} / k T\right)}{C_{S i} \exp \left(E_{S i-i}^{b} /_{k T}\right)+C_{F e} \exp \left(E_{F e-i}^{b} / k T\right)+C_{C r} \exp \left(E_{C r-i}^{b} / k T\right)+C_{N i} \exp \left(E_{N i-i / k T}^{b}\right)}
$$

where $E_{j-i}^{b}\left(\mathrm{j}\right.$ is Fe, $\mathrm{Cr}, \mathrm{Ni}$ and $\mathrm{Si}$ ) is the binding energy between an interstitial $i$ and solute atom $j$. If $E_{j-i}^{b}$ is zero or the same for all elements, then Eq. (7) is reduced to $C_{S i}^{i}=C_{i} C_{S i}$, resulting in the same form as 
that for random occupation of interstitials by Si. When they are different, preferential solute-interstitial complexes form.

\section{Results and Discussions}

\subsection{Dislocations and Frank loops}

The microstructure after irradiation up to 10.2 dpa was the subject of previous studies $[39,40$, 44]. The irradiated microstructure consisted of Frank dislocation loops and fine-scale precipitates typical of neutron irradiations at the temperature investigated [58-61]. To summarize, the loop size increased while the density decreased with increasing dose [39]. Small cavities were observed with sizes near $\sim 2 \mathrm{~nm}[39]$. These studies also investigated the as-received microchemistry near grain boundaries and found limited to no prior segregation of $\mathrm{Fe}, \mathrm{Cr}, \mathrm{Ni}$, or $\mathrm{Si}$ at the grain boundaries [40, 47], indicating that any segregation in the irradiated materials is most likely due to the irradiation. For a detailed description and discussion of the irradiated microstructure and as-received segregation to grain boundaries, the reader is referred to the previous studies.

\subsection{Radiation-induced segregation at different grain boundary structures}

Two specific types of grain boundaries were investigated for RIS: random HA grain boundaries and $\Sigma 3$ grain boundaries. A summary of the grain boundaries investigated and their boundary type classification can be found in Table 3. No attempt was made to classify $\Sigma 3$ grain boundaries based on grain boundary plane. It is recognized that the grain boundary plane is an important parameter as the plane can significantly change the grain boundary properties and the RIS response [25]. As discussed in following sections, all $\Sigma 3$ grain boundaries exhibited almost complete suppression of RIS indicating that a majority, if not all, the $\Sigma 3$ grain boundaries investigated were most likely coherent twins based on the study by Barr et al. [25], although a full five degree parameterization would be needed to conclusively verify.

Neutron irradiated random HA grain boundaries exhibited preferential enrichment of $\mathrm{Ni}$ and $\mathrm{Si}$ to the grain boundaries with corresponding depletion of $\mathrm{Fe}$ and $\mathrm{Cr}$ at all doses, although the magnitude of the RIS response varied with irradiation dose. $\Sigma 3$ grain boundaries exhibited a distinctly different 
behavior than random HA grain boundaries where segregation to the $\Sigma 3$ boundary was suppressed with limited to no variation in the microchemistry across the boundary for all doses investigated. For example, Fig. 1(a) shows 1D segregation profiles for $\mathrm{Ni}, \mathrm{Cr}$, and $\mathrm{Si}$ for the two grain boundary types for the 47.1 dpa specimen. The 1D segregation profiles show a sharp Ni and Si enrichment peak constrained to within several nanometers of the grain boundary with corresponding $\mathrm{Cr}$ depletion for the random $\mathrm{HA}$ grain boundary, while the $\Sigma 3$ grain boundary shows no segregation peaks of any investigated element including $\mathrm{Fe}, \mathrm{Cr}, \mathrm{Ni}$, and $\mathrm{Si}$ within the experimental error of the measurement. The random $\mathrm{HA}$ grain boundary also shows distinct regions of depletion on either side of the enrichment peak for $\mathrm{Ni}$ and a corresponding morphology for Cr. Similar segregation profile morphologies have been observed in neutron and proton irradiated 300 series stainless steels [62-64].

The experimentally observed RIS response at different grain boundary types was consistent with the predicted RIS response generated from the GiMIK model. Figures 1(b) and 1(c) show the calculated 1D segregation profiles and compare them to the experimentally determined profiles. The model parameters for $\mathrm{Fe}, \mathrm{Cr}$, and $\mathrm{Ni}$ used in the calculation were taken from Allen et al. [50]. Due to the lack of diffusivity data for $\mathrm{Si}$ in the austenite (FCC) phase, the following assumptions were made for the modeling parameters for Si. First, because the atomic size of $\mathrm{Si}$ is closer to that of $\mathrm{Ni}$, the parameters for describing Si diffusion through a vacancy mechanism, such as exchanging frequency and migration energy, were assumed to be the same as those of Ni. Second, in the original MIK model, the exchange frequency for $\mathrm{Fe}, \mathrm{Cr}$, and $\mathrm{Ni}$ with interstitials and the migration energy of the $\mathrm{Fe}-, \mathrm{Cr}-$, and $\mathrm{Ni}$ - interstitial complexes were set the same so that there is no preferential coupling between elemental $\mathrm{Fe}$, $\mathrm{Cr}$, or $\mathrm{Ni}$ and interstitials. With the addition of $\mathrm{Si}$, it is assumed that the preferential coupling between elements and interstitials will be exclusively accounted for by the binding energies in Eq. (7), and all other parameters are the same as those for $\mathrm{Fe}, \mathrm{Cr}$, and $\mathrm{Ni}$.

To see the validity of the first assumption, the GiMIK model was initially conducted with all binding energies set to zero, i.e., assuming the inverse Kirkendall mechanism only. The results of this assumption are shown in Fig. 1(b) and showed enrichment of Si and $\mathrm{Ni}$ and the depletion of $\mathrm{Cr}$ at grain 
boundary. These results suggest that by assuming similar diffusivities between $\mathrm{Si}$ and $\mathrm{Ni}$, the inverse Kirkendall mechanism in the MIK model has already shown the correct trend of element segregation. However, the magnitude of enrichment of $\mathrm{Ni}$ and $\mathrm{Si}$ is much smaller and that of $\mathrm{Cr}$ depletion is much larger than the average values determined from experimental measurements. Such inconsistencies between the experimental data and the modeling calculations were observed at all doses and conditions, suggesting that the enrichment of Si observed at boundaries is not exclusively controlled by the inverse Kirkendall mechanism.

To reach a better agreement with the experimental data, the binding energies of $0.012 \mathrm{eV}$ for $\mathrm{Si}$, $0.008 \mathrm{eV}$ for $\mathrm{Cr}$, and $0.003 \mathrm{eV}$ for $\mathrm{Ni}$ were obtained by fitting the calculated composition profiles with experimental ones. No binding energy for Fe is needed. The modeling results are shown in Fig. 1(c), suggesting that the preferential coupling between elements and interstitials exists not only for undersized atoms Si and Ni but also for that oversized atom Cr. Barnard et al. [65] predicted a coupling between $\mathrm{Cr}$ and interstitials, and the interstitial diffusion of $\mathrm{Cr}$ counterbalances the depletion of $\mathrm{Cr}$ at a grain boundary due to vacancy diffusion in an ab-initio molecular dynamics simulation of RIS in Ni-Cr alloys. The findings here are consistent with the results of Barnard et al. The preferential coupling between elements with a vacancy is a major factor leading to the depletion of $\mathrm{Cr}$ and enrichment of $\mathrm{Si}$ and $\mathrm{Ni}$ at the grain boundary. The binding between $\mathrm{Cr}$ and interstitials reduces the depletion effect, and that between Ni/Si and interstitials increases the enrichment of these species. However, these conclusions are drawn with awareness of the pre-existing assumption about exchanging frequency and migration energy of the elements with/via vacancies or interstitials.

Another finding is that the simulated profiles at the region close to the grain boundary do not fully capture the experimental segregation profile, particularly for HA grain boundaries. For instance, the HA grain boundaries typically show small regions of depletion or enrichment next to a primary enrichment or depletion peak, respectively, but such a feature is missing from the simulated profiles. This could be related to the competition between driving forces for segregation when significant segregation is 
observed, but rigorous studies into this effect and optimization of the model based on such an investigation fell out of the scope of work for this study.

Also, it should be noted the simulated segregation profiles are shallower than the experimentally observed ones in both the MIK and GiMIK models. These discrepancies between the experimental data and the modeling data could be due to experimental conditions not quantified during the RIS analysis technique including the specimen thickness and grain boundary tilt to the electron beam. Both factors can greatly affect the observed segregation profile $[66,67]$, especially for sharp profiles like those observed at random HA grain boundaries. Such effects could be the leading factor in the variances observed in Table 3 for boundaries of the same classification. The rate theory model assumes that all investigations are completed with a uniform specimen thickness and perfect orientation of the grain boundary to the electron probe.

The segregation profile is also calculated at the $\Sigma 3$ grain boundary, as shown in Fig. 1c. The misorientation axis of $\Sigma 3$ is set at $\langle 111\rangle$ and the misorientation angle as $59.5^{\circ}$, the average angle from experimental measurements. The interfacial energy of a grain boundary at the exact $\Sigma 3$ orientation was set as $150 \mathrm{~mJ} / \mathrm{m}^{2}$ based on literature data [31]. The GiMIK model allows for deviations from the exact CSL orientation based on the theory proposed by Brandon (also known as the Brandon criterion) [49]. The minimum amount of segregation is anticipated to occur at the exact $\Sigma 3$ CSL orientation, with increasing segregation observed with increasing deviation from the exact $\Sigma 3$ CSL orientation [31]. This effect is the reasoning behind the slight segregation observed at the modeled $\Sigma 3$ grain boundary and the experimental profiles shown in Fig. 1.

The calculated profiles for elements with and without preferential binding of interstitials did not show a difference for the modeled $\Sigma 3$ grain boundary. For both cases, the segregations of all elements at $\Sigma 3$ boundaries were very small. Thus, the deviation from the exact $\Sigma 3$ is dominate in determining the RIS response for $\Sigma 3$ grain boundaries, in contrast with the case of HA grain boundaries, where the on- 
boundary concentration of defects is near thermal equilibrium and the binding energy plays a more significant role in determining the RIS response.

\subsection{Implication of grain boundary structure on sink strength}

Segregations of elements at $\Sigma 3$ boundaries are different from those of random HA grain boundaries. This is because the sink strength of the random HA grain boundary is significantly greater than that of a $\Sigma 3$ grain boundary. For a random HA grain boundary, the sink strength is so significant that the defects are annihilated at a rate which is equivalent to the rate at which they are able to diffuse to the grain boundaries. Therefore, the rate limiting step is the diffusion of mobile point defects from bulk to grain boundary, which subsequently affects the diffusion flux of elements through these defects. The rapid capture and annihilation rate of mobile point defects at a random HA grain boundary essentially maintains the excess concentration of defects in the vicinity of the grain boundary at zero or thermodynamic equilibrium.

On the other hand, the sink strength of the $\Sigma 3$ grain boundary depends on the misorientation angle and the dislocation density. The more the misorientation angle deviates from the exact $\Sigma 3$ grain boundary, the higher the dislocation density, and hence the stronger the sink strength. In this work, the deviations are less than $0.5^{\circ}$ for $\Sigma 3$ grain boundaries. The sink strength of the $\Sigma 3$ grain boundary is thus very low, and the defects are annihilated at a low rate, which becomes the rate limiting step in the defect capture and annihilation process contributing to RIS at $\Sigma 3$ grain boundaries.

The rate of point defect annihilation and concentration at a defect sink can be evaluated directly from the GiMIK model as it calculates the concentration of $\mathrm{Fe}, \mathrm{Cr}, \mathrm{Ni}$, and $\mathrm{Si}$ as well as the concentration of vacancies and interstitials as a function of distance from the defect sink and as a function of irradiation time. For example, the rate difference between random HA grain boundaries and $\Sigma 3$ grain boundaries can be seen in Fig. 2, where the mobile point defect concentration (vacancies and interstitials) predicted by the GiMIK model in the vicinity of a grain boundary as a function of time (or damage dose) is shown. The model shows the random HA grain boundary continuously behaves like a perfect sink so that the 
vacancy concentration is maintained at thermal equilibrium and the interstitial concentration is maintained at zero, as they are in the standard MIK model. With the modified grain boundary condition, the $\Sigma 3$ grain boundary does not perform in the same manner with increasing dose (or time). The defect concentrations at a $\Sigma 3$ boundary accumulate first, and then reach a steady state. The steady state defect concentration is reached when the diffusion rate of mobile defects from bulk to grain boundary equals the rate of mobile point defect annihilation at the $\Sigma 3$ boundary. The difference between vacancy and interstitial concentrations at steady state is due to preferential coupling between solute and vacancy or interstitials. Steady state at $\Sigma 3$ grain boundaries is reached very early-on in the irradiation for the conditions assumed here (on the order of $10 \mathrm{~s}$ or $\sim 8 \times 10^{-6} \mathrm{dpa}$ ).

The accumulation of defects transported from the bulk in the $\Sigma 3$ grain boundary under sink steady state conditions leads to smaller concentration gradients of defects compared to that in the random HA grain boundary. This can be seen in Fig. 3, where the defect concentration gradients are plotted for the 47.1 dpa scenario. The larger concentration gradient of defects at the HA grain boundary leads to the greater driving force for diffusion flux of all elements to the grain boundaries.

The sink strength at random HA grain boundaries is also dynamically changed by composition variations due to RIS. Wolfer [68] indicated that RIS in alloys leads to a composition gradient around point defect sinks and these gradients in turn affect the drift forces and fluxes of mobile point defects. Fig. 4 plots the fluxes of vacancies and interstitials at a random HA grain boundary as a function of dose at $320^{\circ} \mathrm{C}$ as calculated from the GiMIK model to evaluate such an effect. At very low dose, $0.01 \mathrm{dpa}$, the RIS (composition gradient) at the grain boundary is small, and the fluxes of vacancies and interstitials are almost the same, and large. At a higher dose, $0.1 \mathrm{dpa}$, the composition gradient is larger, and the fluxes of both defects are depressed, with that of vacancies being depressed more compared to interstitials. As the dose continues to increase, the same trend in suppressed fluxes is followed. The reduction of the defect flux to the random HA grain boundary and the annihilation of defects at the grain boundary will eventually reach a steady state at which the composition segregation remains unchanged. In contrast, the 
lower point defect annihilation sites at $\Sigma 3$ grain boundaries do not show the same effect; the flux remains unchanged due to the lower concentration gradient. As discussed by Heald and Speight [69], the reduced point defect annihilation sites in the $\Sigma 3$ grain boundaries mean that a limited number of defects are influenced by the drift forces and hence their effect is insignificant at these boundary types compared to random HA grain boundaries. These results suggest that the grain boundary structure will alter the composition variation at a grain boundary due to RIS and therefore will have varying impacts on the sink strength of grain boundaries of different types as a function of dose.

\subsection{Implications on grain boundary structure for RIS as a function of dose}

The random HA grain boundaries showed a variation in the RIS response with irradiation dose, as shown in Table 3 and summarized in Fig. 5. The magnitude of the segregation response was monotonically increasing with the highest segregation observed in the 47.1 dpa specimen at random HA grain boundaries. As noted, the experimentally observed $\Sigma 3$ grain boundaries showed limited to no segregation after irradiation for all doses. These observations are consistent with the results from the GiMIK model, which is plotted as solid lines in Fig. 5. Both experiments and model show a sharp increase in the RIS between the as-received grain boundary concentrations and the 5.5 dpa condition in the random HA grain boundaries. From 5.5 dpa to 10.2 dpa, the change in grain boundary concentration is less and at 10.2, the RIS response is nearly at steady state levels where the random HA grain boundaries reach an on-boundary change in concentration of $\sim 10 \mathrm{wt} \% \mathrm{Ni}$ enrichment, $\sim 5 \mathrm{wt} \% \mathrm{Cr}$ depletion, and $\sim 1$ wt $\%$ Si enrichment. At $47.1 \mathrm{dpa}$, the random HA grain boundaries are at maximum changes in grain boundary concentrations. This trend in the dose dependence of the random HA grain boundaries is consistent with the typically reported segregation trends for neutron irradiated austenitic stainless steels [64].

No significant change was observed in FWHM, with increasing dose with the average FWHM being $3.9 \mathrm{~nm}, 4.0 \mathrm{~nm}$, and $3.7 \mathrm{~nm}$ for the 5.5, 10.2, and $47.1 \mathrm{dpa}$ samples, respectively, for irradiated random HA grain boundaries. The model predicted FWHMs of $6.8 \mathrm{~nm}, 7.0 \mathrm{~nm}$ and $7.3 \mathrm{~nm}$ for the 5.5, 
10.2, and 47.1 dpa samples, respectively. The FWHM provides insight into the mobile point defect concentrations near the grain boundaries. The limited change in the FWHM as a function of dose indicates at higher doses the concentration gradient at the grain boundary remains relatively constant, and hence the RIS is in a steady-state regime. As noted earlier, factors not accounted for such as grain boundary tilt or specimen thickness could contribute to the variances between the model and the experiment.

It should be noted that the calculated results from the GiMIK model reach steady state faster than the experimental observation, which could be attributed to a constant sink strength and density of dislocation sinks used in the GiMIK model. A model describing the relationship between sink strength and density of defect sinks and irradiation time/dose is needed to improve the agreement between experimental observation and modeling results.

Some caution should be taken in assuming the discrepancy between the experiment and the model is explicitly due to missed physics in the model. Although error bars are reported for the magnitude of RIS, error in the reported damage dose and temperature can also be expected. As reported in Ref. [37], extensive neutron dosimetry was performed prior to irradiation to determine the neutron flux in the irradiation positions. The accuracy of these measurements was estimated to be better than $7 \%$, and the radial distribution of the neutron flux was less than $8 \%$. The irradiation test rig had a sodium coolant flow with average variations between the inlet and outlet temperature less than $10 \%$. These variations in irradiation parameters, although quite small, could impact the defect production and migration processes and result in some variation in the magnitude of the RIS response and reported damage dose compared to the idealized nominal parameters used as modeling inputs. Furthermore, the model does not account for multiple reactor cycles used to accomplish the dose observed in the samples.

The discrepancies between the reported values of the model and experimental, especially at low doses, are most likely a convolution of all errors based in both the model and the experiment. Given this, the reasonable agreement, particularly at higher doses, provides reasonable confidence in the reported results. 
Based on the results presented here, $\Sigma 3$ grain boundaries are a defect sink which prevents/limits RIS, but they are not anticipated to influence other known radiation-induced mechanisms in the vicinity of the grain boundary such as Frank loop formation. Simply put, the results presented here indicate that $\Sigma 3$ grain boundaries with low energy in a metallic matrix will limit the amount of RIS occurring in the material system but will not be effective defect sinks, while HA grain boundaries with high energy will be highly susceptible to RIS but will also serve as an effective defect sink, particularly at doses relevant to extended operation or fast fission environments.

\subsection{Implications on RIS and grain boundary structure on phase stability near grain boundaries}

The spectrum images also show an interesting phenomenon with distinct Ni-Si rich clusters observed on $\Sigma 3$ grain boundaries but not in the vicinity or on most HA grain boundaries (Fig. 6). The clusters are apparent in both the $\mathrm{Ni}-\mathrm{K}_{\alpha}$ and $\mathrm{Si}-\mathrm{K}_{\alpha}$ maps in Fig. 6, indicating that the clusters are enriched in both $\mathrm{Ni}$ and $\mathrm{Si}$ over the matrix. These Ni-Si clusters were also observed as a random distribution in the matrix. In spectrum images of both random HA grain boundaries and $\Sigma 3$ grain boundaries, the Ni-Si clusters were, on average, several nanometers in diameter. The compositions of precipitates observed could not be conclusively determined due to significant matrix contributions during analysis. It is expected the Ni-Si clusters are either $\gamma^{\prime}\left(\mathrm{Ni}_{3} \mathrm{Si}\right)$ or G-phase $\left(\mathrm{M}_{6} \mathrm{Ni}_{16} \mathrm{Si}_{7}\right)$ as both phases have been identified in irradiated 304 stainless steels containing sufficient Si [62, 70, 71]. Other analysis techniques, such as atom probe tomography, would be needed to determine the phase(s) present based on composition or diffraction signatures of the Ni-Si clusters. Such techniques fall out of the scope of this work.

Given this, some insight can be drawn through thermodynamic modeling. Yang and Busby have developed thermodynamic models for the major precipitate phases in the 304 and 316 stainless steels [72]. Details about the modeling methods can be found in Ref. [72]. For the 304 alloy investigated in this study, thermodynamic calculation results suggest that G-phase based on $\mathrm{M}_{6} \mathrm{Ni}_{16} \mathrm{Si}_{7}(\mathrm{M}=\mathrm{Cr}, \mathrm{Mn})$ is a thermodynamically stable phase in the low temperature regime $\left(200-400^{\circ} \mathrm{C}\right)$, as shown in Fig. 7 . For phases that are thermodynamically stable at such a low temperature, it is rarely shown in the 
microstructure of samples under a normal period of thermal aging time due to extremely slow diffusion kinetics. However, for samples under high doses of irradiation, the densities of defects such as point defects, Frank loops, and dislocations are greatly enhanced. Yang and Busby have shown that increasing dislocation density can greatly enhance the precipitation kinetics of the low-temperature thermally stable phases [72].

The observation of isolated Ni-Si clusters at the $\Sigma 3$ boundaries observed here suggested that its formation is associated with dislocation cores which comprise a grain boundary or possible other incoherent regions such as steps/ledges along the boundary not explicitly resolved during lower-resolution STEM investigations. The lack of discrete Ni-Si cluster formation at random HA grain boundaries where the solution segregation is the greatest suggested that the formation of Ni-Si clusters is not strongly dependent on solute segregation. The observation that Ni-Si clusters are randomly distributed in the matrix suggested that their formation is either associated with preferential nucleation sites such as line dislocations, Frank loops, or other point defects, or with chemically driven homogeneous nucleation. In either case, the precipitation kinetics can be significantly accelerated by enhanced diffusion due to increased density of mobile point defects in irradiated samples. The segregation of solute Ni and $\mathrm{Si}$ in the vicinity of defect sinks may assist in the precipitation of the G-phase; however, the chemical driving force of the bulk thermodynamics plays a significant role. Once the chemical driving force is available, the precipitation at dislocations and Frank loops is usually more prevalent than at grain boundaries due to more nucleation sites, shorter diffusion distance, and preferential crystallographic orientation.

\section{Conclusions}

A neutron irradiated 304 stainless steel was investigated for RIS both experimentally and using rate theory-based modeling. Here, RIS was used as a metric to understand the sink characteristics of different grain boundary structures and infer their sink characteristics up to high dose ( $>40 \mathrm{dpa})$. The RIS response was found to be suppressed at $\Sigma 3$ grain boundaries even to high dose, while HA grain boundaries exhibited the highest degree of RIS. Based on modeling calculations, it can be inferred that 
HA grain boundaries perform near the perfect sink criteria while $\Sigma 3$ grain boundaries have a lower sink strength due to the density of point defect annihilation sites varying at each boundary type. The sink characteristics of the different grain boundary types had more global implications, including the formation of Ni-Si clusters on $\Sigma 3$ grain boundaries; no evidence of a secondary phase formation on HA grain boundaries was found. Based on these results, one could assume specialized grain boundary networks could be developed through grain boundary engineering which limit the percolation pathway for corrosion through RIS susceptible grain boundaries while still maintaining high sink strengths through random HA grain boundaries.

\section{Acknowledgements}

Experiments by KGF were sponsored by the U.S. Department of Energy, Office of Nuclear Energy, for the Light Water Reactor Sustainability Research and Development Effort. MIK/GiMIK modeling by YY was sponsored by the U.S. Department of Energy, Office of Nuclear Energy, for the Nuclear Enabling Technology (NEET0 Program as part of the Reactor Materials effort). Assessment of the GiMIK model and development of sink strength concepts by KGF was sponsored by the Materials Sciences and Engineering Division, Office of Basic Energy Sciences, U.S. Department of Energy. A part of the microscopy work by KGF was conducted at the Center for Nanophase Materials Sciences (CNMS), which is a DOE Office of Science User Facility. The authors would like to thank Dr. L. Tan and Dr. M. N. Gussev from Oak Ridge National Laboratory (ORNL) for their fruitful discussions about the results. YY would also like to thank Dr. T. S. Duh for the discussion on the GiMIK model development. 


\section{Tables and Figures Captions}

Table 1: Input parameters to the GiMIK model

Table 2: Input parameters to modify boundary conditions on the GiMIK model

Table 3: Summary of grain boundaries investigated using STEM-EDS for a 304 stainless steel irradiated in the BOR-60 reactor. On-boundary compositions were determined by curve fitting a Gaussian peak to the 1D segregation profiles. Variance was determined by one standard deviation of the mean through binning the spectrum images.

Figure 1: 1D concentration profiles from random HA and $\Sigma 3$ grain boundaries showing the RIS response of different grain boundary types in the $47.1 \mathrm{dpa}$ irradiated specimen. (a) Experimentally determined profile of a $\Sigma 3$ grain boundary (GB16 in Table 3) and a random HA grain boundary (RHAGB) (GB15 in Table 3). (b) GiMIK model for a random HA grain boundary without consideration of binding energy (B.E.) between solutes and interstitials. (c) GiMIK model with consideration of binding energy between solutes and interstitials calculated RIS profile at $\Sigma 3$ grain boundary and a RHAGB for comparison to the experimental profiles.

Figure 2: Concentration of vacancies and interstitials at $\Sigma 3$ and random HA grain boundary (RHAGB) as a function of dose. The interstitial concentration at the RHAGB is set to zero and not shown here.

Figure 3: Concentration of vacancies and interstitials as a function of distance at $\Sigma 3$ and random high angle grain boundary (RHAGB) irradiated to $47.1 \mathrm{dpa}$ at $320^{\circ} \mathrm{C}$ as calculated from the GiMIK model.

Figure 4: Flux of vacancies and interstitials as a function of distance at a random high angle grain boundary with increasing dose at $320^{\circ} \mathrm{C}$ as calculated from the GiMIK model.

Figure 5: Average on boundary concentrations of $\mathrm{Ni}, \mathrm{Cr}$, and $\mathrm{Si}$ in the neutron-irradiated 304SS as a function of dose at $320^{\circ} \mathrm{C}$ from random $\mathrm{HA}$ grain boundaries (RHAGB) and $\Sigma 3$ grain boundaries as determined experimentally and using the GiMIK model.

Figure 6: High angle annular dark field (HAADF) and elemental EDS maps extracted from spectrum images showing the Ni-Si cluster formations near grain boundaries in the 47.1 dpa specimen. Grain boundaries run top to bottom of the page as indicated. (a) Random HA grain boundary (GB14 in Table 3). (b) $\Sigma 3$ grain boundary (GB17 in Table 3 ).

Figure 7: Mole fractions of phases in 304 A alloy as a function of temperature. The insert shows enlarged portion of precipitate phases with mole fractions less than 0.05 . 


\section{References}

[1] E.E. Bloom, J.T. Busby, C.E. Duty, P.J. Maziasz, T.E. McGreevy, B.E. Nelson, B.A. Pint, P.F. Tortorelli, S.J. Zinkle, Critical questions in materials science and engineering for successful development of fusion power, Journal of Nuclear Materials, 367-370 (2007) 1-10.

[2] S. Zinkle, J. Busby, Structural materials for fission and fusion energy, Materials Today, 12 (2009) 1219.

[3] S.J. Zinkle, A. Möslang, T. Muroga, H. Tanigawa, Multimodal options for materials research to advance the basis for fusion energy in the ITER era, Nuclear Fusion, 53 (2013) 104024.

[4] X.-M. Bai, L.J. Vernon, R.G. Hoagland, A.F. Voter, M. Nastasi, B.P. Uberuaga, Role of atomic structure on grain boundary-defect interactions in $\mathrm{Cu}$, Physical Review B, 85 (2012).

[5] N. Doan, G. Martin, Elimination of irradiation point defects in crystalline solids: Sink strengths, Physical Review B, 67 (2003).

[6] A.D. Brailsford, L.K. Mansur, The effect of precipitate-matrix interface sinks on the growth of voids in the matrix, Journal of Nuclear Materials, 103-104 (1981) 1403-1408.

[7] C. Jiang, N. Swaminathan, J. Deng, D. Morgan, I. Szlufarska, Effect of grain boundary stresses on sink strength, Materials Research Letters, 2 (2014) 100-106.

[8] A. Certain, S. Kuchibhatla, V. Shutthanandan, D.T. Hoelzer, T.R. Allen, Radiation stability of nanoclusters in nano-structured oxide dispersion strengthened (ODS) steels, Journal of Nuclear Materials, 434 (2013) 311-321.

[9] A.G. Certain, K.G. Field, T.R. Allen, M.K. Miller, J. Bentley, J.T. Busby, Response of nanoclusters in a 9Cr ODS steel to $1 \mathrm{dpa}, 525^{\circ} \mathrm{C}$ proton irradiation, Journal of Nuclear Materials, 407 (2010) 2-9.

[10] T.R. Allen, J. Gan, J.I. Cole, M.K. Miller, J.T. Busby, S. Shutthanandan, S. Thevuthasan, Radiation response of a 9 chromium oxide dispersion strengthened steel to heavy ion irradiation, Journal of Nuclear Materials, 375 (2008) 26-37.

[11] D.T. Hoelzer, J. Bentley, M.A. Sokolov, M.K. Miller, G.R. Odette, M.J. Alinger, Influence of particle dispersions on the high-temperature strength of ferritic alloys, Journal of Nuclear Materials, 367370, Part A (2007) 166-172.

[12] M.K. Miller, D.T. Hoelzer, Effect of neutron irradiation on nanoclusters in MA957 ferritic alloys, Journal of Nuclear Materials, 418 (2011) 307-310. 
[13] M.K. Miller, E.A. Kenik, K.F. Russell, L. Heatherly, D.T. Hoelzer, P.J. Maziasz, Atom probe tomography of nanoscale particles in ODS ferritic alloys, Materials Science and Engineering: A, 353 (2003) 140-145.

[14] M.K. Miller, K.F. Russell, D.T. Hoelzer, Characterization of precipitates in MA/ODS ferritic alloys, Journal of Nuclear Materials, 351 (2006) 261-268.

[15] P.D. Edmondson, C.M. Parish, Y. Zhang, A. Hallén, M.K. Miller, Helium bubble distributions in a nanostructured ferritic alloy, Journal of Nuclear Materials, 434 (2013) 210-216.

[16] P. Pareige, M.K. Miller, R.E. Stoller, D.T. Hoelzer, E. Cadel, B. Radiguet, Stability of nanometersized oxide clusters in mechanically-alloyed steel under ion-induced displacement cascade damage conditions, Journal of Nuclear Materials, 360 (2007) 136-142.

[17] M.S. El-Genk, J.-M. Tournier, A review of refractory metal alloys and mechanically alloyed-oxide dispersion strengthened steels for space nuclear power systems, Journal of Nuclear Materials, 340 (2005) 93-112.

[18] S. Jitsukawa, A. Kimura, A. Kohyama, R.L. Klueh, A.A. Tavassoli, B. van der Schaaf, G.R. Odette, J.W. Rensman, M. Victoria, C. Petersen, Recent results of the reduced activation ferritic/martensitic steel development, Journal of Nuclear Materials, 329-333 (2004) 39-46.

[19] W.Z. Han, M.J. Demkowicz, E.G. Fu, Y.Q. Wang, A. Misra, Effect of grain boundary character on sink efficiency, Acta Materialia, 60 (2012) 6341-6351.

[20] L. Tan, T.R. Allen, J.T. Busby, Grain boundary engineering for structure materials of nuclear reactors, Journal of Nuclear Materials, 441 (2013) 661-666.

[21] L. Tan, K. Sridharan, T.R. Allen, R.K. Nanstad, D.A. McClintock, Microstructure tailoring for property improvements by grain boundary engineering, Journal of Nuclear Materials, 374 (2008) 270280.

[22] T.D. Shen, S. Feng, M. Tang, J.A. Valdez, Y. Wang, K.E. Sickafus, Enhanced radiation tolerance in nanocrystalline $\mathrm{MgGa}_{2} \mathrm{O}_{4}$, Applied Physics Letters, 90 (2007) 263115.

[23] Y. Chimi, A. Iwase, N. Ishikawa, M. Kobiyama, T. Inami, S. Okuda, Accumulation and recovery of defects in ion-irradiated nanocrystalline gold, Journal of Nuclear Materials, 297 (2001) 355-357.

[24] C. Sun, K.Y. Yu, J.H. Lee, Y. Liu, H. Wang, L. Shao, S.A. Maloy, K.T. Hartwig, X. Zhang, Enhanced radiation tolerance of ultrafine grained $\mathrm{Fe}-\mathrm{Cr}-\mathrm{Ni}$ alloy, Journal of Nuclear Materials, 420 (2012) 235-240.

[25] C.M. Barr, G.A. Vetterick, K.A. Unocic, K. Hattar, X.-M. Bai, M.L. Taheri, Anisotropic radiationinduced segregation in 316L austenitic stainless steel with grain boundary character, Acta Materialia, 67 (2014) 145-155.

[26] M. Tomozawa, Y. Miyahara, K. Kako, Solute segregation on $\Sigma 3$ and random grain boundaries in type 316L stainless steel, Materials Science and Engineering: A, 578 (2013) 167-173. 
[27] R. Hu, G.D.W. Smith, E.A. Marquis, Effect of grain boundary orientation on radiation-induced segregation in a Fe-15.2 at.\% Cr alloy, Acta Materialia, 61 (9) (2013), 3490-3498.

[28] E.A. Marquis, S. Lozano-Perez, V. de Castro, Effects of heavy-ion irradiation on the grain boundary chemistry of an oxide-dispersion strengthened Fe-12 wt.\% Cr alloy, Journal of Nuclear Materials, 417 (2011) 257-261.

[29] N. Sakaguchi, S. Watanabe, H. Takahashi, R.G. Faulkner, A multi-scale approach to radiationinduced segregation at various grain boundaries, Journal of Nuclear Materials, 329-333 (2004) 11661169.

[30] T.S. Duh, J.J. Kai, F.R. Chen, Effects of grain boundary misorientation on solute segregation in thermally sensitized and proton-irradiated 304 stainless steel, Journal of Nuclear Materials, 283-287 (2000) 198-204.

[31] T.S. Duh, J.J. Kai, F.R. Chen, L.H. Wang, Numerical simulation modeling on the effects of grain boundary misorientation on radiation-induced solute segregation in 304 austenitic stainless steels, Journal of Nuclear Materials, 294 (2001) 267-273.

[32] K.G. Field, L.M. Barnard, C.M. Parish, J.T. Busby, D. Morgan, T.R. Allen, Dependence on grain boundary structure of radiation induced segregation in a $9 \mathrm{wt} . \% \mathrm{Cr}$ model ferritic/martensitic steel, Journal of Nuclear Materials, 435 (2013) 172-180.

[33] K.G. Field, B.D. Miller, H.J.M. Chichester, K. Sridharan, T.R. Allen, Relationship between lath boundary structure and radiation induced segregation in a neutron irradiated $9 \mathrm{wt} . \% \mathrm{Cr}$ model ferritic/martensitic steel, Journal of Nuclear Materials, 445 (2014) 143-148.

[34] S. Watanabe, Y. Takamatsu, N. Sakaguchi, H. Takahashi, Sink effect of grain boundary on radiationinduced segregation in austenitic stainless steel, Journal of Nuclear Materials, 283-287 (2000) 152-156.

[35] N. Sakaguchi, M. Endo, S. Watanabe, H. Kinoshita, S. Yamashita, H. Kokawa, Radiation-induced segregation and corrosion behavior on $\Sigma 3$ coincidence site lattice and random grain boundaries in protonirradiated type-316L austenitic stainless steel, Journal of Nuclear Materials, 434 (2013) 65-71.

[36] G.-G. Lee, H.-H. Jin, Y.-B. Lee, J. Kwon, Observation and rate theory modeling of grain boundary segregation in $\Sigma 3$ twin boundaries in ion-irradiated stainless steel 316, Journal of Nuclear Materials, 449 (2014) 234-241.

[37] J.P. Massoud, P. Dubuisson, P. Scott, V.K. Chamardine, CIR II Program: Description of the Boris 6 and 7 Experiments in the BOR-60 Fast Breeder Reactor, in EPRI 1011787, Palo Alto, CA, 2005.

[38] P. Scott, Materials Reliability Program: A Review of the Cooperative Irradiation Assisted Stress Corrosion Cracking Research Program (MRP-98), in EPRI 1002807, Palo Alto, CA, 2003.

[39] L. Tan, K.G. Field, M.N. Gussev, J.T. Busby, Microstructural Evolution of Type 304 Variants and 316 Stainless Steels under Neutron Irradiation, in 16th International Conference on Environmental Degadation of Materials in Nuclear Power Systems-Water Reactors, Asheville, NC, 2013.

[40] D.J. Edwards, A. Schemer-Kohrn, S. Bruemmer, Characterization of Neutron-Irradiated 300-Series Stainless Steels, in EPRI 1009896, Palo Alto, CA, 2006. 
[41] K.J. Stephenson, G.S. Was, Crack initiation behavior of neutron irradiated model and commercial stainless steels in high temperature water, Journal of Nuclear Materials, 444 (2014) 331-341.

[42] K.J. Stephenson, G. Was, Comparison of the microstructure, deformation and crack initiation behavior of austenitic stainless steel irradiated in-reactor or with protons, Journal of Nuclear Materials, 456 (2014) 85-98.

[43] L. Tan, J. Busby, Alloying effect of $\mathrm{Ni}$ and $\mathrm{Cr}$ on irradiated microstructural evolution of type 304 stainless steels, Journal of Nuclear Materials, 443 (2013) 351-358.

[44] D. Edwards, E. Simonen, S.M. Bruemmer, P. Efsing, Microstructural evolution in neutron-irradiated stainless steels: comparison of LWR and fast reactor irradiations, in T. Allen, P.J. King, L. Nelson (Eds.) 12th International Conference on Environmental Degradation of Materials in Nuclear Power System Water Reactors, The Minerals, Metals \& Materials Society, 2005, pp. 419-428.

[45] K.G. Field, M.N. Gussev, J.T. Busby, Microstructural Characterization of Deformation Localization at Small Strains in a Neutron-Irradiated 304 Stainless Steel, Journal of Nuclear Materials, 452 (2014) 500-508.

[46] M.N. Gussev, K.G. Field, J. Busby, Strain-induced phase transformation at the surface of an AISI304 stainless steel irradiated to $4.4 \mathrm{dpa}$ and deformed to $0.8 \%$ strain, Journal of Nuclear Materials, 446 (2014) 187-192.

[47] D.J. Edwards, S.M. Bruemmer, Characterization of CIR II Irradiated Stainless Steels, in EPRI EPP19021/C9406, Palo Alto, CA, 2008.

[48] J.-J. Fundenberger, A. Morawiec, E. Bouzy, J.S. Lecomte, Polycrystal orientation maps from TEM, Ultramicroscopy, 96 (2003) 127-137.

[49] D.G. Brandon, The structure of high-angle grain boundaries, Acta Metallurgica, 14 (1966) 14791484.

[50] T.R. Allen, G.S. Was, Modeling radiation-induced segregation in austenitic $\mathrm{Fe}-\mathrm{Cr}-\mathrm{Ni}$ alloys, Acta Materialia, 46 (1998) 3679-3691.

[51] J.M. Perks, A.D. Marwick, C.A. English, Computer code to calculate radiation induced segregation in concentrated ternary alloys, in AERE-R-12121, 1986, p. 48.

[52] T.R. Allen, G.S. Was, E.A. Kenik, The effect of alloy composition on radiation-induced segregation in Fe-Cr-Ni alloys, J. Nucl. Mater., 244 (1997) 278-294.

[53] T.R. Allen, Modeling of Radiation-Induced Segregation in Austenitic Fe-Cr-Ni Alloys, in, University of Michigan, 1997.

[54] M.J. Hackett, R. Najafabadi, G.S. Was, Modeling solute-vacancy trapping at oversized solutes and its effect on radiation-induced segregation in Fe-Cr-Ni alloys, Journal of Nuclear Materials, 389 (2009) 279-287.

[55] P. Doig, D. Lonsdale, P.E.J. Flewitt, Quantitative microanalysis with high spatial resolution, The Metals Society, London, 1981. 
[56] P. Doig, D. Lonsdale, P.E.J. Flewitt, The spatial resolution of X-ray microanalysis in the scanning transmission electron microscope, Philosophical Magazine A, 41 (1980) 761-775.

[57] H. Wiedersich, P.R. Okamoto, N.Q. Lam, A theory of radiation-induced segregation in concentrated alloys, Journal of Nuclear Materials, 83 (1979) 98-108.

[58] P.L. Lane, P.J. Goodhew, Dislocation loops at twin boundaries in an ion-irradiated austenitic alloy, Philosophical Magazine A, 46 (1982) 597-606.

[59] F. Garner, D.S. Gelles, Irradiation Creep Mechanisms: An Experimental Perspective, Journal of Nuclear Materials, 159 (1988) 286-309.

[60] J.J. Holmes, R.E. Robbins, J.L. Brimhall, B. Mastel, Elevated Temperature Irradiation Hardening In Austenitic Stainless Steel, Acta Materialia, 16 (1968) 1968.

[61] D.J. Edwards, E.P. Simonen, F.A. Garner, L.R. Greenwood, B.M. Oliver, S.M. Bruemmer, Influence of irradiation temperature and dose gradients on the microstructural evolution in neutron-irradiated 316SS, Journal of Nuclear Materials, 317 (2003) 32-45.

[62] Z. Jiao, G.S. Was, Novel features of radiation-induced segregation and radiation-induced precipitation in austenitic stainless steels, Acta Materialia, 59 (2011) 1220-1238.

[63] S. Bruemmer, E. Simonen, P. Scott, P.L. Andersen, G. Was, J.L. Nelson, Radiation-induced material changes and susceptibility to intergranular failure of light-water-reactor core internals, Journal of Nuclear Materials, 274 (1999) 299-314.

[64] K. Fukuya, Current understanding of radiation-induced degradation in light water reactor structural materials, Journal of Nuclear Science and Technology, 50 (2013) 213-254.

[65] L. Barnard, J.D. Tucker, S. Choudhury, T.R. Allen, D. Morgan, Modeling radiation induced segregation in Ni-Cr model alloys from first principles, Journal of Nuclear Materials, 425 (2012) 8-15.

[66] I.A. Vatter, J.M. Titchmarsh, Measurement of grain-boundary segregation by STEM-EDX analysis, Ultramicroscopy, 28 (1989) 236-239.

[67] C.M. Parish, K.G. Field, A. Certain, J.P. Wharry, Application of STEM Characterization for Investigating Radiation Effects in BCC Fe-based Alloys, Submitted to Journal of Materials Research, (2014).

[68] W.G. Wolfer, Drift forces on vacancies and interstitials in alloys with radiation-induced segregation, Journal of Nuclear Materials, 114 (1983) 292-304.

[69] P.T. Heald, M.V. Speight, Point Defect Behavior in Irradiated Materials, Acta Metallurgica, 23 (1975) 1389-1399.

[70] K.C. Russell, Phase Stability Under Irradiation, Progress in Materials Science, 28 (1984) 229-434.

[71] L. E.H., P.J. Maziasz, A.F. Rowcliffe, Phase stability during irradiation: proceedings of a symposium sponsored by the Nuclear Metallurgy Committee at the Fall Meeting of The Metallurgical Society of AIME, in J.R. Holland, L.K. Mansur, D.J. Potter (Eds.) Phase Stability During Irradiation, The Metallurgical Society of AIME, Pittsburgh, PA, 1980, pp. 191-218. 
[72] Y. Yang, J.T. Busby, Thermodynamic modeling and kinetics simulation of precipitate phases in AISI 316 stainless steels, Journal of Nuclear Materials, 448 (2014) 282-293. 


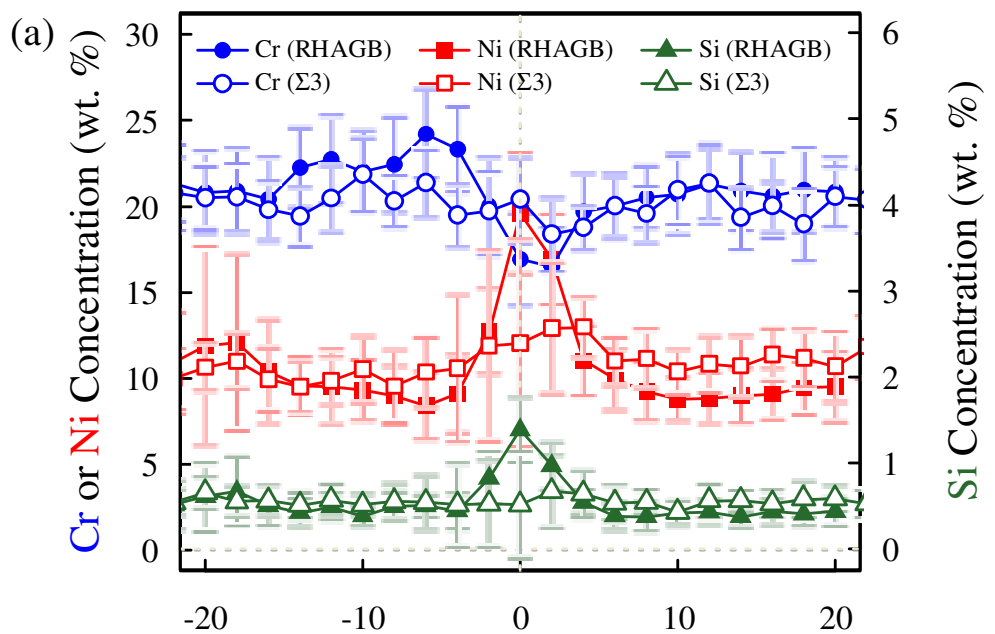

Distance From Grain Boundary (nm)

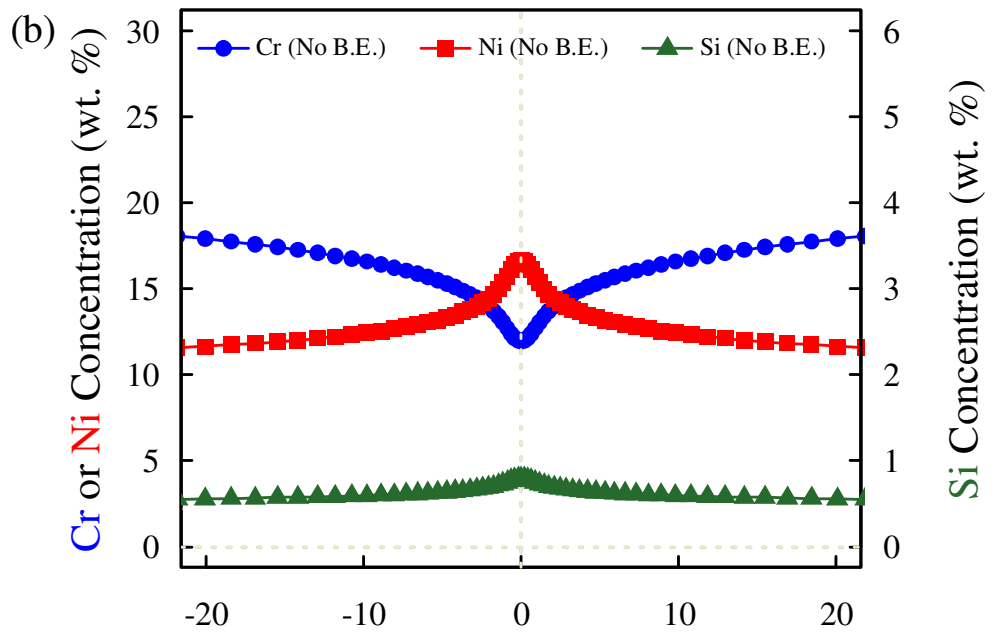

Distance From Grain Boundary (nm)

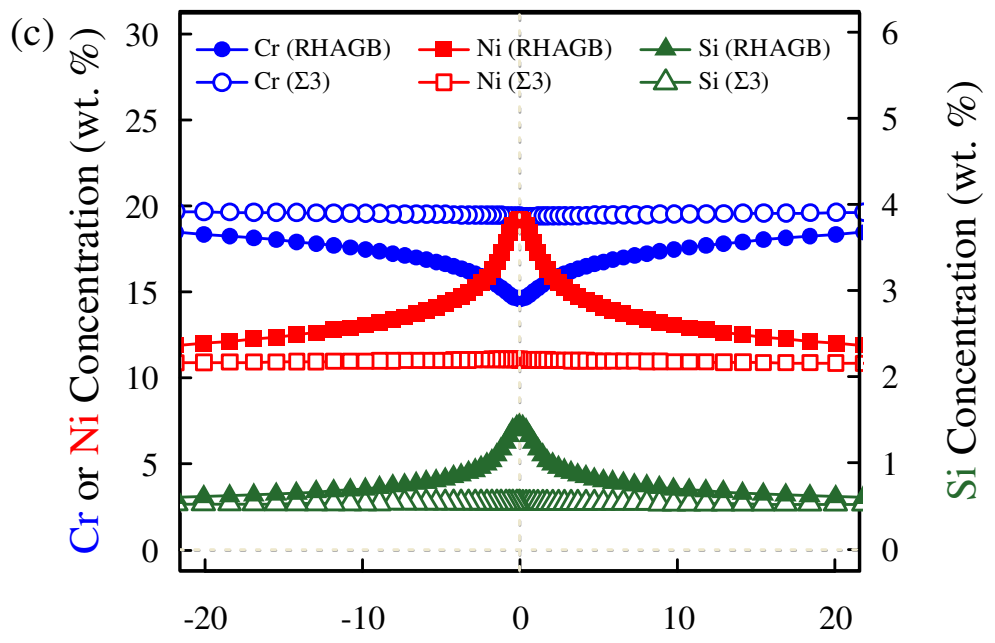

Distance From Grain Boundary (nm) 
Figure 1: 1D concentration profiles from random HA and $\Sigma 3$ grain boundaries showing the RIS response of different grain boundary types in the 47.1 dpa irradiated specimen. (a) Experimentally determined profile of a $\Sigma 3$ grain boundary (GB16 in Table 3) and a random HA grain boundary (RHAGB) (GB15 in Table 3). (b) GiMIK model for a random HA grain boundary without consideration of binding energy (B.E.) between solutes and interstitials. (c) GiMIK model with consideration of binding energy between solutes and interstitials calculated RIS profile at $\Sigma 3$ grain boundary and a RHAGB for comparison to the experimental profiles.

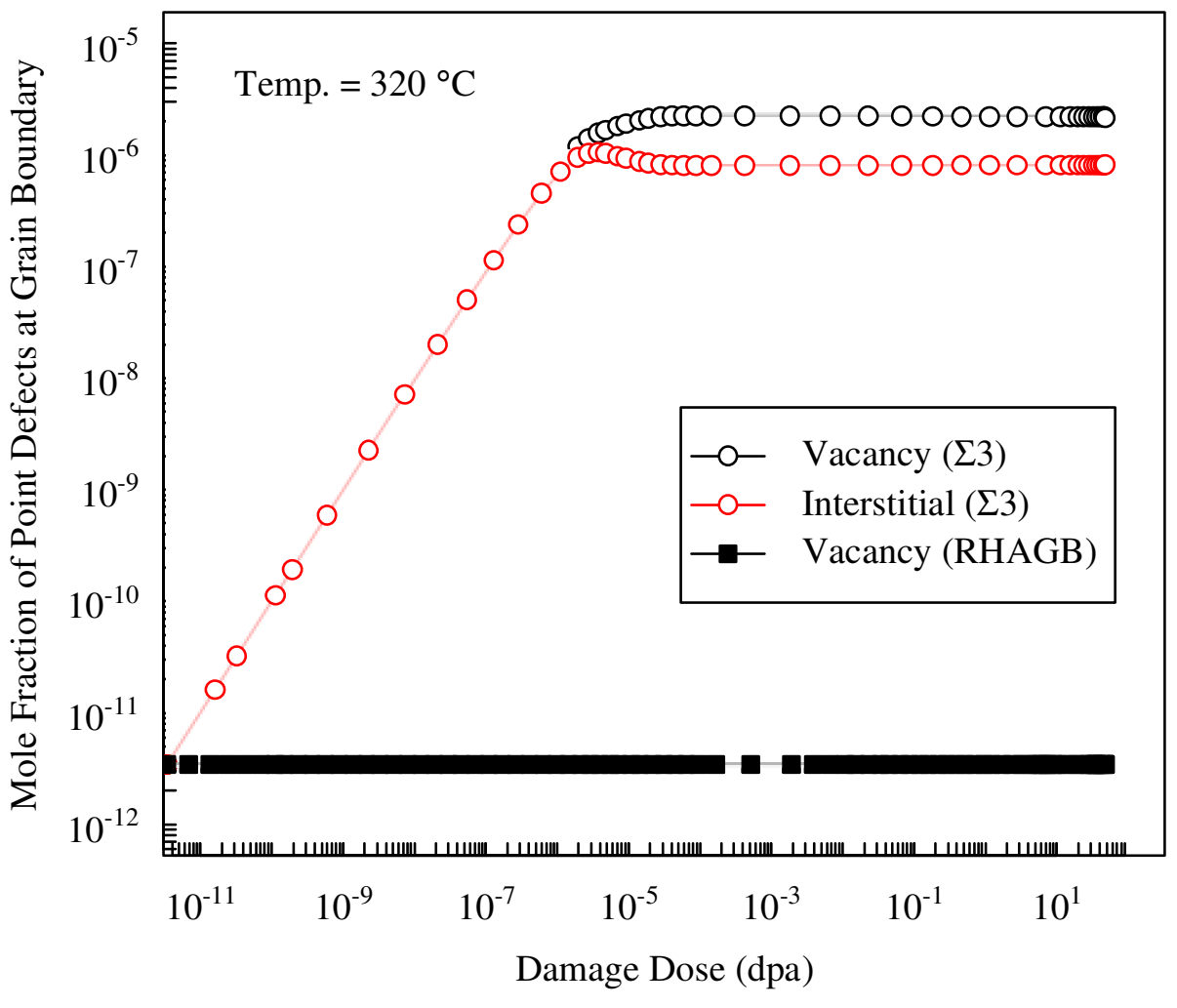

Figure 2: Concentration of vacancies and interstitials at $\Sigma 3$ and random HA grain boundary (RHAGB) as a function of dose. The interstitial concentration at the RHAGB is set to zero and not shown here. 


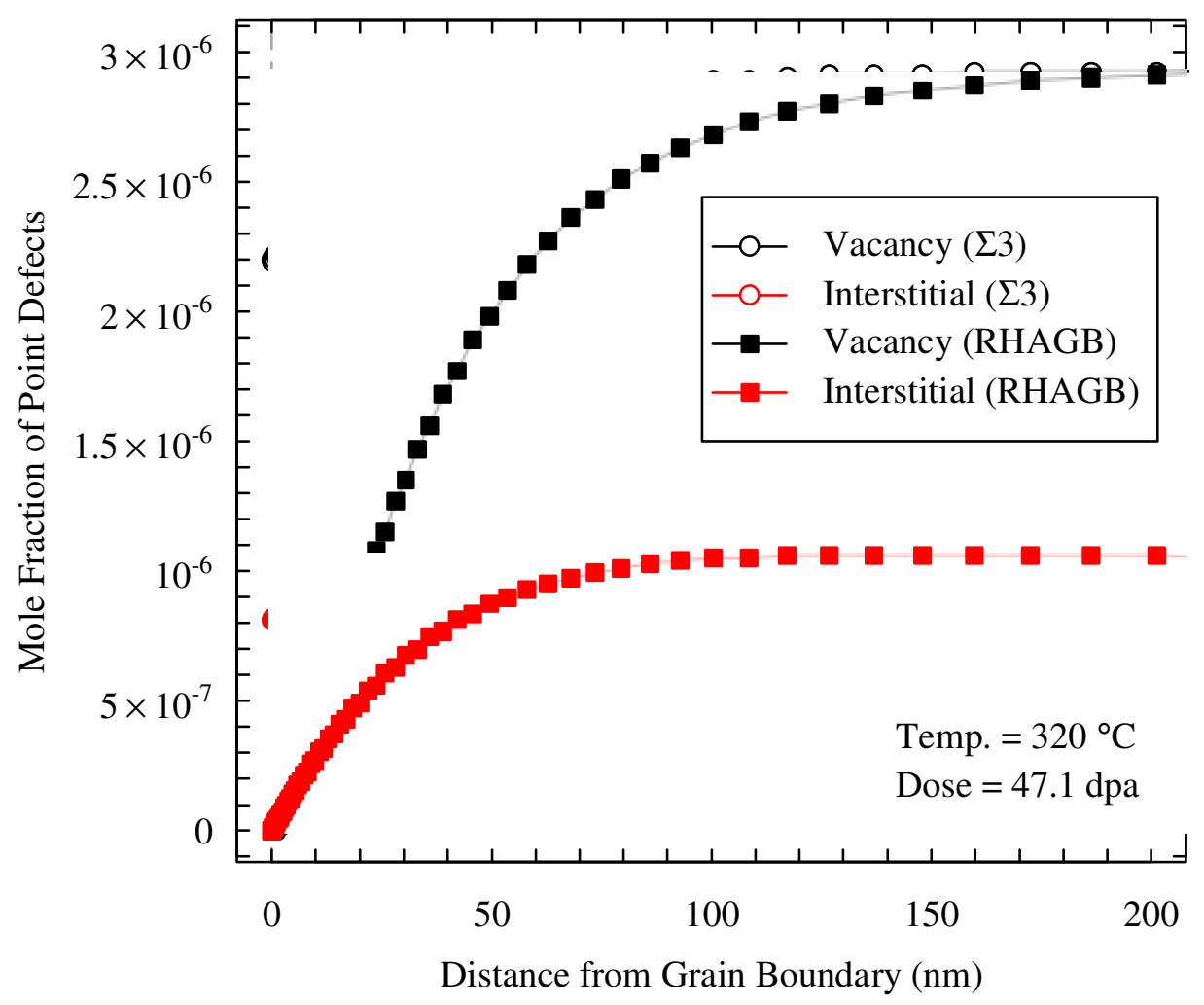

Figure 3: Concentration of vacancies and interstitials as a function of distance at $\Sigma 3$ and random high angle grain boundary (RHAGB) irradiated to $47.1 \mathrm{dpa}$ at $320^{\circ} \mathrm{C}$ as calculated from the GiMIK model. 


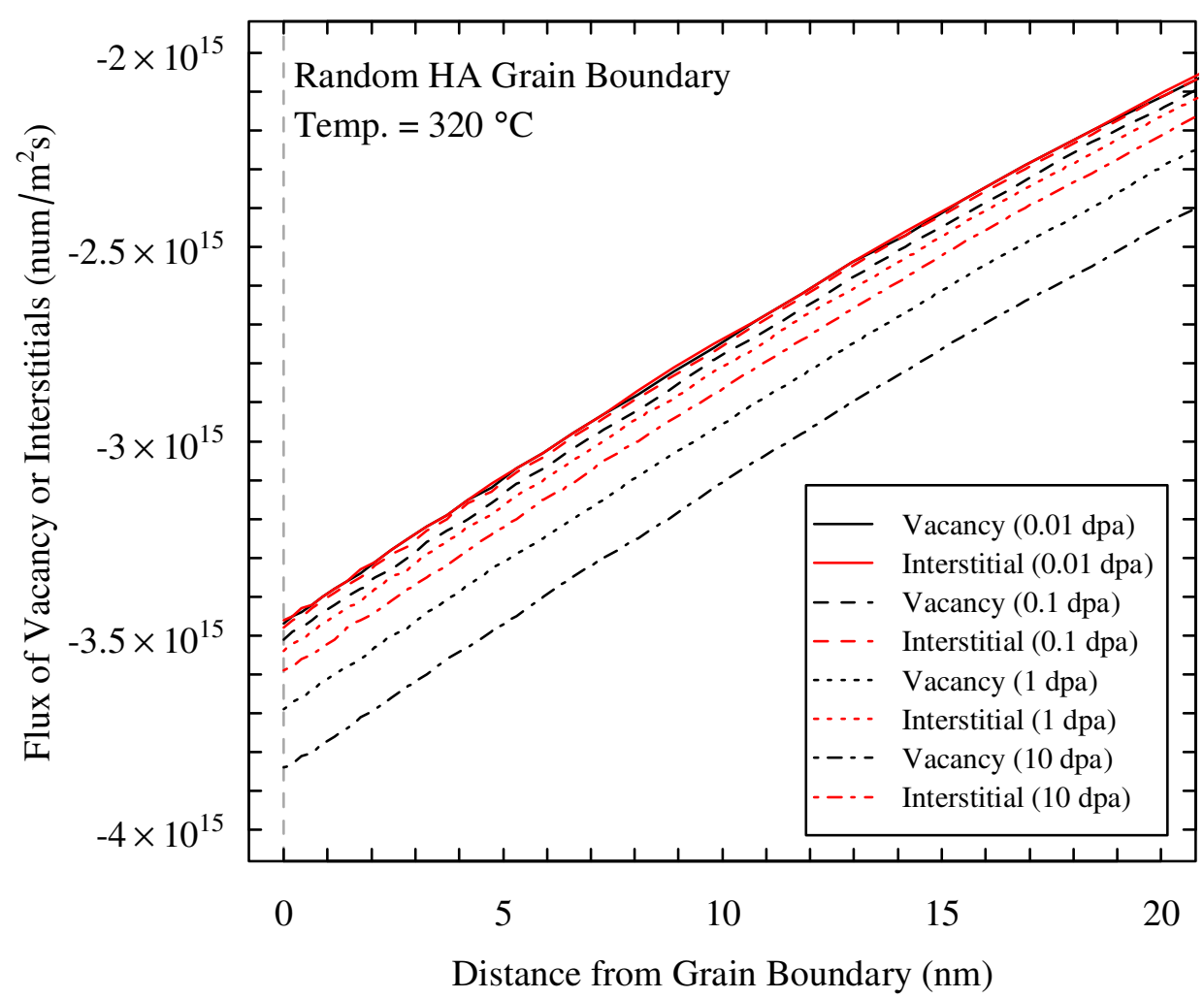

Figure 4: Flux of vacancies and interstitials as a function of distance at a random high angle grain boundary with increasing dose at $320^{\circ} \mathrm{C}$ as calculated from the GiMIK model. 


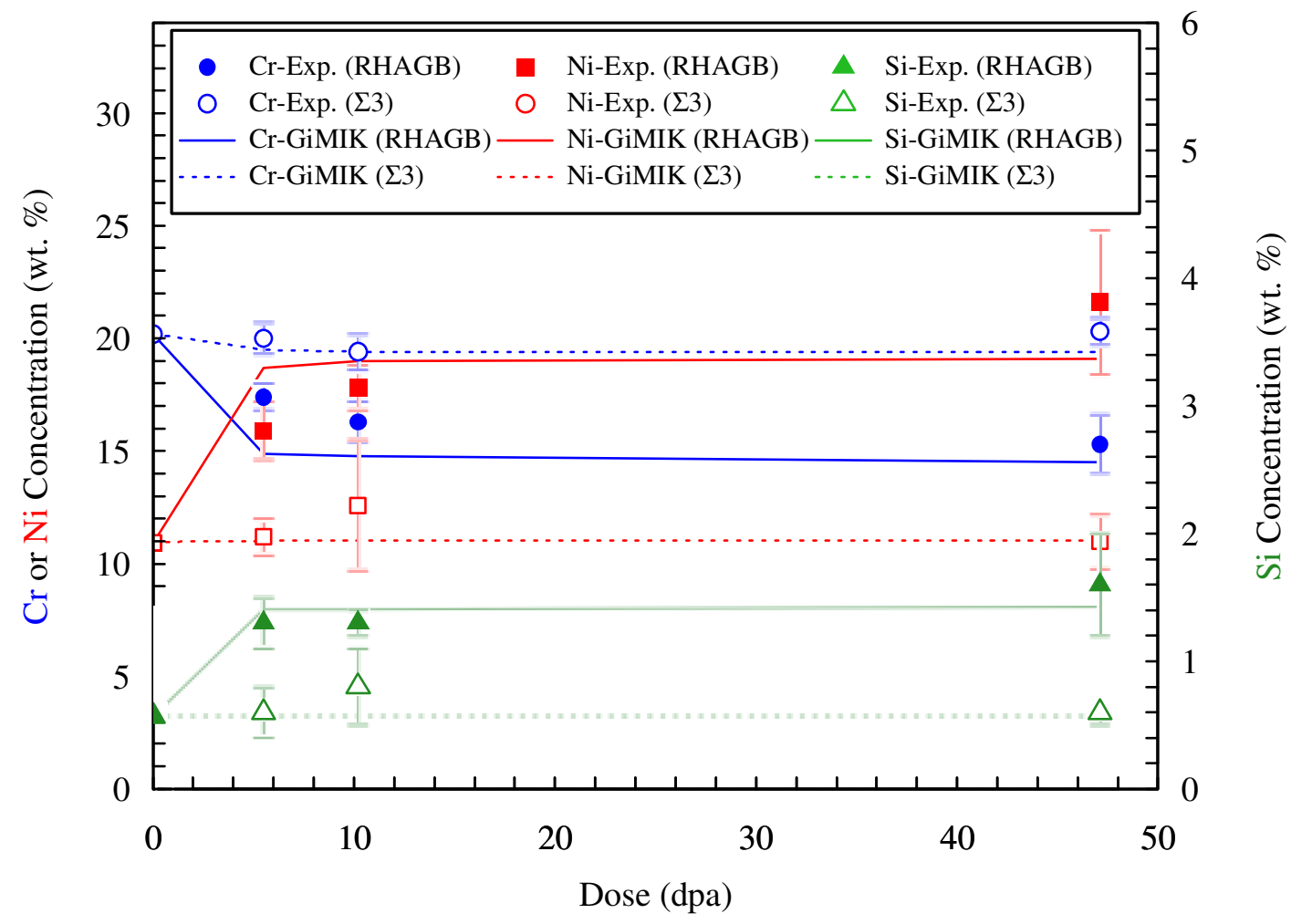

Figure 5: Average on boundary concentrations of $\mathrm{Ni}, \mathrm{Cr}$, and $\mathrm{Si}$ in the neutron-irradiated 304SS as a function of dose at $320^{\circ} \mathrm{C}$ from random HA grain boundaries (RHAGB) and $\Sigma 3$ grain boundaries as determined experimentally and using the GiMIK model. 
a)

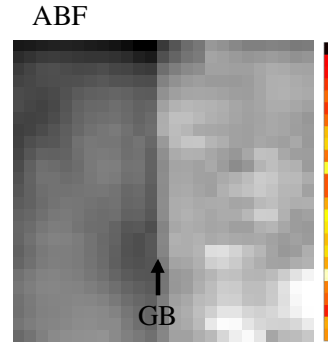
Fe $K_{\alpha}$

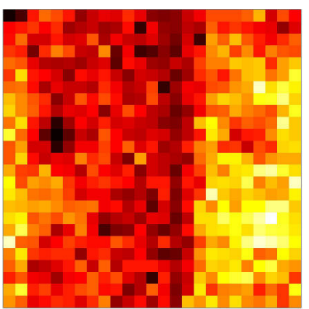

Cr K

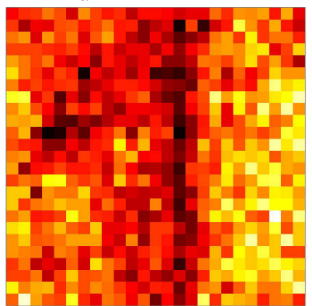

Ni K

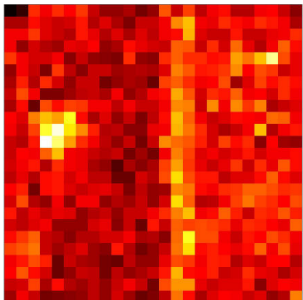

Si K ${ }_{\alpha}$

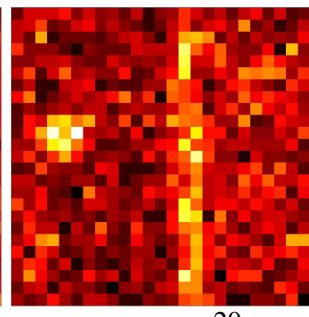

$20 \mathrm{~nm}$

b) $\mathrm{ABF}$
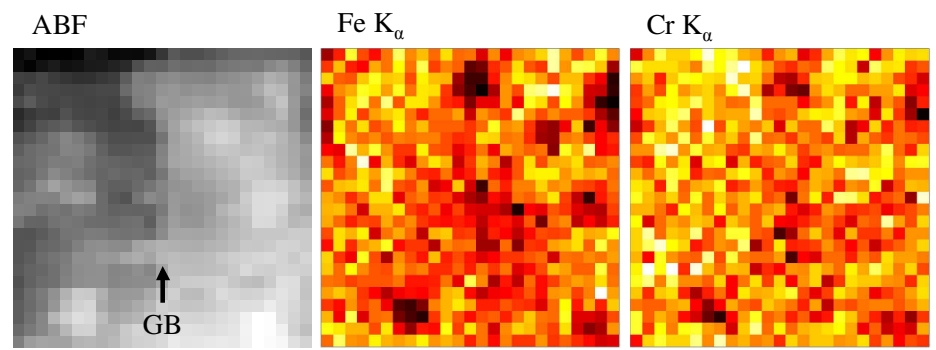

$\mathrm{Ni} \mathrm{K}$

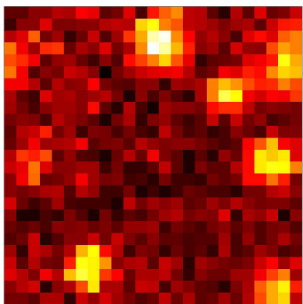

Si K $\alpha$

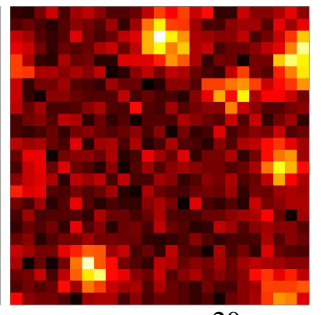

Figure 6: High angle annular dark field (HAADF) and elemental EDS maps extracted from spectrum images showing the Ni-Si cluster formations near grain boundaries in the 47.1 dpa specimen. Grain boundaries run top to bottom of the page as indicated. (a) Random HA grain boundary (GB14 in Table 3). (b) $\Sigma 3$ grain boundary (GB17 in Table 3). 


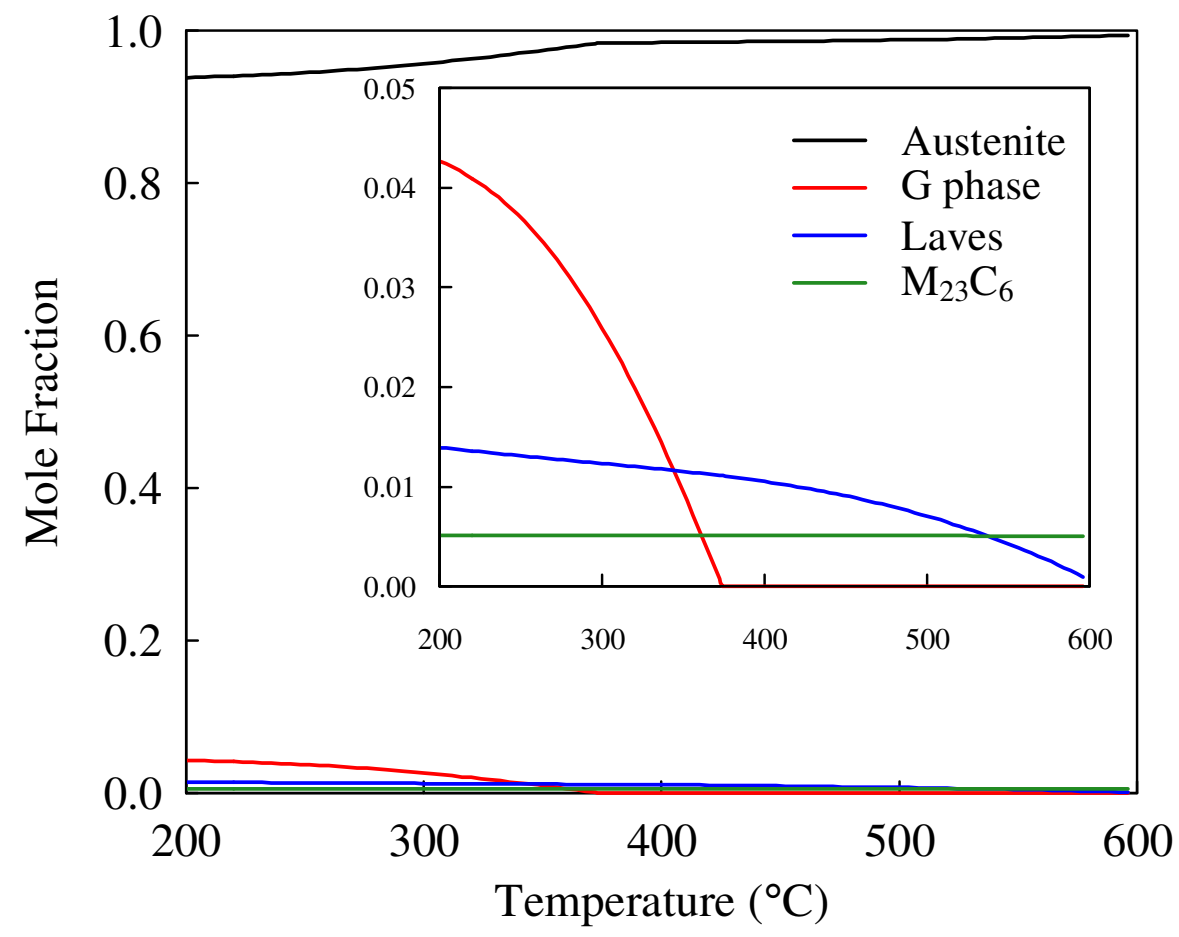

Figure 7: Mole fractions of phases in $304 \mathrm{~A}$ alloy as a function of temperature. The insert shows enlarged portion of precipitate phases with mole fractions less than 0.05 . 
Table 1: Input parameters to the GiMIK model

\begin{tabular}{|l|l|l|}
\hline Symbol & Definition & Values \\
\hline$\omega_{F e}$ & Vacancy jump frequency for $\mathrm{Fe}$ & $1.6 \times 10^{13} \mathrm{~s}^{-1}$ \\
\hline$\omega_{C r}$ & Vacancy jump frequency for $\mathrm{Cr}$ & $2.4 \times 10^{13} \mathrm{~s}^{-1}$ \\
\hline$\omega_{N i}$ & Vacancy jump frequency for $\mathrm{Ni}$ & $1 \times 10^{13} \mathrm{~s}^{-1}$ \\
\hline$\omega_{S i}$ & Vacancy jump frequency for $\mathrm{Ni}$ & $1 \times 10^{13} \mathrm{~s}^{-1}$ \\
\hline$f_{v}^{F e}$ & Fe-vacancy correlation factor & 1 \\
\hline$f_{v}^{C r}$ & Cr-vacancy correlation factor & 1 \\
\hline$f_{v}^{N i}$ & Ni-vacancy correlation factor & 1 \\
\hline$f_{v}^{S i}$ & Si-vacancy correlation factor & 1 \\
\hline$E_{v}^{F e}$ & Vacancy migration energy for $\mathrm{Fe}$ & $1.28 \mathrm{eV}$ \\
\hline$E_{v}^{C r}$ & Vacancy migration energy for $\mathrm{Cr}$ & $0.97 \mathrm{eV}$ \\
\hline$E_{v}^{N i}$ & Vacancy migration energy for $\mathrm{Ni}$ & $1.04 \mathrm{eV}$ \\
\hline$f_{i}$ & Atom-interstitial correlation factor & 0.44 \\
\hline$v_{i}$ & Interstitial jump frequency & $1.5 \times 10^{12} \mathrm{~s}^{-1}$ \\
\hline$E_{m}^{i}$ & Interstitial migration energy & $0.9 \mathrm{eV}$ \\
\hline$\rho$ & Dislocation density & $1.0 \times 10^{14} \mathrm{~m}^{-2}$ \\
\hline$\eta$ & Mobile defect production efficiency & 1 \\
\hline
\end{tabular}


Table 2: Input parameters to modify boundary conditions on the GiMIK model

\begin{tabular}{|l|l|l|}
\hline Symbol & Definition & Values \\
\hline$S_{H}$ & Sink strength at high angle grain boundary & $\frac{1}{\frac{d_{H}}{2}-\gamma_{0}}$ \\
\hline$S_{L}$ & Sink strength at low angle grain boundary & $\frac{\pi}{\ln \left(\frac{d}{2 \gamma_{0}}\right)}$ \\
\hline $\mathrm{d}_{\mathrm{H}}$ & Distance between grain boundary dislocations (HA) & $\frac{b}{4 \delta} \frac{1}{\sin \left(\frac{\Delta \theta}{2}\right)} \mathrm{m}$ \\
\hline $\mathrm{d}_{\mathrm{L}}$ & Distance between grain boundary dislocations (LA) & $\frac{b}{\theta} \mathrm{m}$ \\
\hline$\gamma_{0}$ & The radius of grain boundary dislocations & $3.647 \times 10^{-10} \mathrm{~m}$ \\
\hline$g_{V}$ & a dimensionless constant depending on the structure & 1 \\
\hline$a$ & Lattice constant & $3.647 \times 10^{-10} \mathrm{~m}$ \\
\hline$Z_{V}$ & Coordination number & 12 \\
\hline$f_{v}^{g b}$ & Vacancy correlation factor at grain boundary & 0.5 \\
\hline$v_{V j, g b}^{0}$ & vibrational frequency of $j$ atom at grain boundary & $v_{V j, b u l k}^{0}$ \\
\hline$E_{V j, g b}^{M}$ & $\begin{array}{l}\text { the migration energy for diffusion of a vacancy via } j \\
\text { atom in the grain boundary }\end{array}$ & $E_{V j, b u l k}^{M}-\frac{a^{2}}{n} \gamma_{g b}$ \\
\hline$n$ & $\begin{array}{l}\text { The number of atomic layers inside the grain } \\
\text { boundary }\end{array}$ & 1 \\
\hline$\gamma_{g b}$ & $\begin{array}{l}\text { Interfacial energy of random high angle grain } \\
\text { boundary }\end{array}$ & $\frac{\gamma_{g b c}}{1-\frac{1}{\sqrt{\Sigma}}}$ \\
\hline$\gamma_{g b c}$ & Interfacial energy of $\Sigma 3$ grain boundary & $150 \mathrm{~mJ} / \mathrm{m}^{2}$ \\
\hline$\delta$ & Grain boundary thickness. & $2.5 \times 10^{-10} \mathrm{~m}$ \\
\hline$b_{H}$ & $\begin{array}{l}\text { Burgers vector of the secondary grain boundary } \\
\text { dislocations }\end{array}$ & $\frac{a}{\sqrt{\Sigma}}$ \\
\hline$\Sigma$ & Type of CSL boundary & 3 \\
\hline$b_{L}$ & $\begin{array}{l}\text { Burgers vector of the primary grain boundary } \\
\text { dislocations }\end{array}$ & $3.647 \times 10^{-10} \mathrm{~m}$ \\
\hline$\Delta \theta_{H}$ & Disorientation angle & $8.617 \times 10^{-5} \mathrm{ev} / \mathrm{K}$ \\
\hline$k$ & Boltzmann constant & $\theta_{L}-60^{\circ}$ \\
\hline & & \\
\hline$\theta_{L}$ & & \\
\hline & & \\
\hline
\end{tabular}


Table 3: Summary of grain boundaries investigated using STEM-EDS for a 304 stainless steel irradiated in the BOR-60 reactor. On-boundary compositions were determined by curve fitting a Gaussian peak to the $1 \mathrm{D}$ segregation profiles. Variance was determined by one standard deviation of the mean through binning the spectrum images.

\begin{tabular}{|c|c|c|c|c|c|c|c|c|c|c|}
\hline ID & $\begin{array}{c}\text { Irr. } \\
\text { Temp. } \\
\left({ }^{\circ} \mathrm{C}\right)\end{array}$ & $\begin{array}{c}\text { Irr. } \\
\text { Dose } \\
\text { (dpa) }\end{array}$ & $\begin{array}{c}\text { GB } \\
\text { Type }\end{array}$ & $\begin{array}{l}\text { Mis. } \\
\text { Angle }\end{array}$ & $\begin{array}{l}\text { Mis. } \\
\text { Axis }\end{array}$ & $\begin{array}{c}\mathrm{Fe} \text { at } \\
\text { GB } \\
\text { (wt \%) }\end{array}$ & $\begin{array}{c}\mathrm{Cr} \text { at } \\
\mathrm{GB} \\
(\mathrm{wt} \%)\end{array}$ & $\begin{array}{c}\mathrm{Ni} \text { at } \\
\text { GB } \\
(\text { wt } \% \text { ) }\end{array}$ & $\begin{array}{c}\text { Si at } \\
\text { GB } \\
(\text { wt } \%)\end{array}$ & $\begin{array}{c}\text { FWH } \\
\text { M of } \\
\mathrm{Ni} \\
\text { Peak } \\
(\mathrm{nm})\end{array}$ \\
\hline GB1 & 320 & 5.5 & HA & $29.9^{\circ}$ & $<\overline{54} 1>$ & $\begin{array}{c}64.2 \pm \\
2.6\end{array}$ & $\begin{array}{c}17.4 \pm \\
1.8\end{array}$ & $\begin{array}{c}15.6 \pm \\
1.8\end{array}$ & $\begin{array}{c}1.1 \pm \\
0.3\end{array}$ & 4.7 \\
\hline GB2 & 320 & 5.5 & HA & $48.1^{\circ}$ & $<9 \overline{1} 6>$ & $\begin{array}{c}63.7 \pm \\
1.8\end{array}$ & $\begin{array}{c}16.7 \pm \\
1.2\end{array}$ & $\begin{array}{c}16.6 \pm \\
1.4\end{array}$ & $\begin{array}{c}1.5 \pm \\
0.2\end{array}$ & 3.3 \\
\hline GB3 & 320 & 5.5 & HA & $40.5^{\circ}$ & $<\overline{54} 1>$ & $\begin{array}{c}64.4 \pm \\
2.1\end{array}$ & $\begin{array}{c}18.7 \pm \\
1.6\end{array}$ & $\begin{array}{c}14.2 \pm \\
2.4\end{array}$ & $\begin{array}{c}1.0 \pm \\
0.3\end{array}$ & 5.6 \\
\hline GB4 & 320 & 5.5 & $\Sigma 3$ & $59.3^{\circ}$ & $<\overline{11} 1>$ & $\begin{array}{c}66.2 \pm \\
2.1\end{array}$ & $\begin{array}{c}19.4 \pm \\
2.0\end{array}$ & $\begin{array}{c}12.0 \pm \\
1.9\end{array}$ & $\begin{array}{c}0.7 \pm \\
0.2\end{array}$ & $\mathrm{n} / \mathrm{a}$ \\
\hline GB5 & 320 & 5.5 & $\Sigma 3$ & $59.4^{\circ}$ & $<1 \overline{11}>$ & $\begin{array}{c}66.7 \pm \\
2.3\end{array}$ & $\begin{array}{c}20.7 \pm \\
1.8\end{array}$ & $\begin{array}{c}10.4 \pm \\
1.7\end{array}$ & $\begin{array}{c}0.4 \pm \\
0.2\end{array}$ & $\mathrm{n} / \mathrm{a}$ \\
\hline GB6 & 320 & 5.5 & $\Sigma 3$ & $60.0^{\circ}$ & $<\overline{11} 1>$ & $\begin{array}{c}66.4 \pm \\
1.7\end{array}$ & $\begin{array}{c}19.9 \pm \\
1.9\end{array}$ & $\begin{array}{c}11.2 \pm \\
1.5\end{array}$ & $\begin{array}{c}0.6 \pm \\
0.2\end{array}$ & $\mathrm{n} / \mathrm{a}$ \\
\hline GB7 & 320 & 10.2 & HA & $39.0^{\circ}$ & $<417>$ & $\begin{array}{c}63.3 \pm \\
2.8\end{array}$ & $\begin{array}{c}16.9 \pm \\
1.9\end{array}$ & $\begin{array}{c}16.8 \pm \\
2.6\end{array}$ & $\begin{array}{c}1.2 \pm \\
0.4\end{array}$ & 5.2 \\
\hline GB8 & 320 & 10.2 & HA & $51.6^{\circ}$ & $<23 \overline{2}>$ & $\begin{array}{c}62.1 \pm \\
1.7\end{array}$ & $\begin{array}{c}15.7 \pm \\
1.6\end{array}$ & $\begin{array}{c}18.8 \pm \\
1.7\end{array}$ & $\begin{array}{c}1.3 \pm \\
0.2\end{array}$ & 3.6 \\
\hline GB9 & 320 & 10.2 & $\Sigma 3$ & $58.8^{\circ}$ & $<11 \overline{1}>$ & $\begin{array}{c}64.2 \pm \\
1.7\end{array}$ & $\begin{array}{c}17.9 \pm \\
1.4\end{array}$ & $\begin{array}{c}14.6 \pm \\
1.8\end{array}$ & $\begin{array}{c}1.0 \pm \\
0.3\end{array}$ & 4.2 \\
\hline GB10 & 320 & 10.2 & $\Sigma 3$ & $57.9^{\circ}$ & $<\overline{44} 3>$ & $\begin{array}{c}66.1 \pm \\
1.3\end{array}$ & $\begin{array}{c}20.9 \pm \\
1.2\end{array}$ & $\begin{array}{c}10.5 \pm \\
1.3\end{array}$ & $\begin{array}{c}0.6 \pm \\
0.1\end{array}$ & $\mathrm{n} / \mathrm{a}$ \\
\hline GB11 & 320 & 47.1 & HA & 56.5 & $<21 \overline{2}>$ & $\begin{array}{c}53.9 \pm \\
3.2\end{array}$ & $\begin{array}{c}13.1 \pm \\
1.7\end{array}$ & $\begin{array}{c}27.4 \pm \\
3.8\end{array}$ & $\begin{array}{c}2.4 \pm \\
0.5\end{array}$ & 3.0 \\
\hline GB12 & 320 & 47.1 & HA & 53.2 & $<\overline{7} 61>$ & $\begin{array}{c}61.4 \pm \\
3.1\end{array}$ & $\begin{array}{c}17.2 \pm \\
1.7\end{array}$ & $\begin{array}{c}18.4 \pm \\
2.4\end{array}$ & $\begin{array}{c}1.2 \pm \\
0.3\end{array}$ & 5.6 \\
\hline GB13 & 320 & 47.1 & HA & 44.4 & $<014>$ & $\begin{array}{c}58.3 \pm \\
1.8\end{array}$ & $\begin{array}{c}14.5 \pm \\
1.3\end{array}$ & $\begin{array}{c}24.6 \pm \\
1.8\end{array}$ & $\begin{array}{c}1.8 \pm \\
0.2\end{array}$ & 2.8 \\
\hline GB14 & 320 & 47.1 & HA & 50.7 & $<5 \overline{31}>$ & $\begin{array}{c}60.6 \pm \\
2.1\end{array}$ & $\begin{array}{c}15.0 \pm \\
1.9\end{array}$ & $\begin{array}{c}21.0 \pm \\
2.7\end{array}$ & $\begin{array}{c}1.4 \pm \\
0.4\end{array}$ & 3.4 \\
\hline GB15 & 320 & 47.1 & HA & 54.7 & $<\overline{211}>$ & $\begin{array}{c}60.0 \pm \\
4.1\end{array}$ & $\begin{array}{c}15.9 \pm \\
2.7\end{array}$ & $\begin{array}{c}20.5 \pm \\
3.5\end{array}$ & $\begin{array}{c}1.4 \pm \\
0.4\end{array}$ & 3.4 \\
\hline GB16 & 320 & 47.1 & $\Sigma 3$ & 59.9 & $<111>$ & $\begin{array}{c}66.5 \pm \\
2.6\end{array}$ & $\begin{array}{c}20.2 \pm \\
2.2\end{array}$ & $\begin{array}{c}10.9 \pm \\
1.9\end{array}$ & $\begin{array}{c}0.6 \pm \\
0.2\end{array}$ & $\mathrm{n} / \mathrm{a}$ \\
\hline GB17 & 320 & 47.1 & $\Sigma 3$ & 59.5 & $<111>$ & $\begin{array}{c}66.9 \pm \\
2.3\end{array}$ & $\begin{array}{c}21.1 \pm \\
1.9\end{array}$ & $\begin{array}{c}9.8 \pm \\
1.6\end{array}$ & $\begin{array}{c}0.5 \pm \\
0.2\end{array}$ & $\mathrm{n} / \mathrm{a}$ \\
\hline GB18 & 320 & 47.1 & $\Sigma 3$ & 59.8 & $<\overline{1} 1 \overline{1}>$ & $\begin{array}{c}65.5 \pm \\
4.0\end{array}$ & $\begin{array}{c}19.5 \pm \\
2.1\end{array}$ & $\begin{array}{c}12.2 \pm \\
4.7\end{array}$ & $\begin{array}{c}0.5 \pm \\
0.2\end{array}$ & $\mathrm{n} / \mathrm{a}$ \\
\hline
\end{tabular}

